\title{
Linking African Easterly Wave Activity with Equatorial Waves and the Influence of Rossby Waves from the Southern Hemisphere
}

\author{
GUI-YING YANG \\ National Centre for Atmospheric Science, and Department of Meteorology, \\ University of Reading, Reading, United Kingdom \\ JOHN METHVEN \\ Department of Meteorology, University of Reading, Reading, United Kingdom \\ STEVE WoOLnOUGH \\ National Centre for Atmospheric Science, and Department of Meteorology, \\ University of Reading, Reading, United Kingdom \\ KeVIN Hodges AND BRIAN Hoskins \\ Department of Meteorology, University of Reading, Reading, United Kingdom
}

(Manuscript received 16 June 2017, in final form 22 February 2018)

\begin{abstract}
A connection is found between African easterly waves (AEWs), equatorial westward-moving mixed Rossby-gravity (WMRG) waves, and equivalent barotropic Rossby waves (RWs) from the Southern Hemisphere (SH). The amplitude and phase of equatorial waves is calculated by projection of broadbandfiltered ERA-Interim data onto a horizontal structure basis obtained from equatorial wave theory. Mechanisms enabling interaction between the wave types are identified. AEWs are dominated by a vorticity wave that tilts eastward below the African easterly jet and westward above: the tilt necessary for baroclinic wave growth. However, a strong relationship is identified between amplifying vorticity centers within AEWs and equatorial WMRG waves. Although the waves do not phase lock, positive vorticity centers amplify whenever the cross-equatorial motion of the WMRG wave lies at the same longitude in the upper troposphere (southward flow) and east of this in the lower troposphere (northward flow). Two mechanisms could explain the vorticity amplification: vortex stretching below the upper-tropospheric divergence and ascent associated with latent heating in convection in the lower-tropospheric moist northward flow.

In years of strong AEW activity, $\mathrm{SH}$ and equatorial upper-tropospheric zonal winds are more easterly. Stronger easterlies have two effects: (i) they Doppler shift WMRG waves so that their period varies little with wavenumber (3-4 days) and (ii) they enable westward-moving RWs to propagate into the tropical waveguide from the SH. The RW phase speeds can match those of WMRG waves, enabling sustained excitation of WMRG. The WMRG waves have an eastward group velocity with wave activity accumulating over Africa and invigorating AEWs at similar frequencies through the vorticity amplification mechanism.
\end{abstract}

\section{Introduction}

African easterly waves (AEWs) are lower-tropospheric disturbances initiating, growing, and propagating westward across northern Africa into the tropical Atlantic and sometimes continuing across to the Caribbean Sea (Burpee 1972; Avila and Pasch 1992). AEWs usually appear in May

Corresponding author: Gui-Ying Yang, g.y.yang@reading.ac.uk and activity continues until October or November. They dominate precipitation over West Africa, modulating rainfall through the initiation and organization of mesoscale convective systems and squall lines (Carlson 1969b; Duvel 1990; Diedhiou et al.1999; Fink and Reiner 2003; Mekonnen et al. 2006; Crétat et al. 2015), which produce intense precipitation. Mesoscale convective systems account for over $80 \%$ of total annual rainfall in the Sahel (e.g., Laurent et al. 1998; Mathon et al. 2002). AEWs exhibit 
strong interannual variability: a major influence on the occurrence of precipitation and climate impacts across the region. Here, a key aim is to identify the physical mechanisms that are important to AEW amplification, propagation, and the variability in wave activity.

AEWs are observed to have a period of 3-5 days (Burpee 1972) and a westward phase speed of about $8-10 \mathrm{~m} \mathrm{~s}^{-1}$ (Reed et al. 1977; Price et al. 2007). Their typical zonal wavelength has been reported to be $2000-2800 \mathrm{~km}$ (zonal wavenumber $k=14-19$ ) in early studies (e.g., Carlson 1969a; Burpee 1974, 1975; Reed et al. 1977) but to be longer (3000-5000 km, $k=8-13)$ in some later studies (e.g., Diedhiou et al. 1999; Kiladis et al. 2006).

Cyclonic vorticity centers within AEWs seed a large proportion of tropical cyclones over the North Atlantic (Frank 1970; Avila and Pasch 1992; Landsea 1993; Landsea et al. 1998; Thorncroft and Hodges 2001), with about $60 \%$ of Atlantic tropical cyclones and weak hurricanes originating from AEWs and approximately $85 \%$ of intense hurricanes developing from AEWs (Landsea 1993). It has also been suggested that nearly all of the tropical cyclones that occur in the east Pacific can be associated with AEWs propagating from the Atlantic (Serra et al. 2010) and possibly traced back to Africa (Avila and Pasch 1995). Therefore, understanding the amplification, intensity, and phase speeds of AEWs is important for weather forecasting in the tropics and extratropics.

However, despite a long history of research on AEWs, understanding of the mechanisms behind the dynamics and variability of AEWs is still qualitative and incomplete. Furthermore, there are severe deficiencies in the simulation of the initiation, amplitude, and phase speeds of AEWs in both numerical weather prediction (Berry et al. 2007; Agustí-Panareda et al. 2010) and climate simulations. There are a number of studies relating interannual variability in AEWs to the global circulation of the atmosphere. For example, Nicholson (2009) argued, using one wet and one dry year across West Africa, that the strongest difference in the largescale flow between the years was seen in the upper troposphere, rather than in the lower troposphere at the level of the African easterly jet. The year with stronger precipitation had stronger monthly mean ascending motion in the West African rain belt, stronger divergent outflow (equatorward flow south of the rain belt) and a stronger tropical easterly jet (in the equatorial upper troposphere). These observations are all consistent with a stronger meridional circulation (local Hadley cell) across Africa. However, the link with AEW activity was unexplained.

Elsewhere across the tropics, envelopes of active convection and the location of convective systems are also frequently observed to be related to the structure of large-scale waves. Equatorial waves with an internal first baroclinic mode structure in the vertical including the Kelvin, mixed Rossby-gravity, and Rossby waves identified from different branches of the dispersion relation derived by Matsuno (1966), are fundamental components of the tropical climate system and have been shown to dominate precipitation variability across tropical ocean basins (e.g., Wheeler and Kiladis 1999; Yang et al. 2007a; Yang and Hoskins 2013).

Equatorial waves are trapped near the equator but can propagate in the zonal and vertical directions. Yang et al. (2007a, 2011, 2012) and Yang and Hoskins (2013, 2016) found that the tropical winds and the geopotential anomaly from meteorological analysis data project strongly onto the equatorial wave modes based on the theory of a resting atmosphere. Figure 1 shows the horizontal structures of the three gravest (lowest meridional wavenumber $n$ ) westwardmoving equatorial wave modes: the $n=0$ westwardmoving mixed Rossby-gravity (WMRG) wave and $n=1$ and 2 Rossby waves (denoted R1 and R2). It is seen that although they are equatorially trapped, they can have strong rotational and divergent motions off the equator at a distance determined by the horizontal structure of each mode and a single "trapping scale" [see Eq. (5)]. A major theoretical challenge is that the zonal flow across the tropical Atlantic and Africa (north of the equator) is strongly sheared with the existence of the African easterly jet (AEJ-peaking at $600 \mathrm{hPa}$ near $10^{\circ}-20^{\circ} \mathrm{N}$ ) and the tropical easterly jet (TEJ-around $200 \mathrm{hPa}$ closer to the equator). The shear on the AEJ is thought to be essential to the existence of AEWs through baroclinic and barotropic shear instability (Hall et al. 2006; Cornforth et al. 2017). In contrast, equatorial wave theory does not deal with shear, which is why the horizontal modes (Fig. 1) are untilted in the zonal direction. Nevertheless, the equatorial wave structures form a useful orthogonal basis where the horizontal velocity components and geopotential are coherent. A key modification resulting from vertical wind shear is that the data projected onto the horizontal structures at each level reveals coherent wave modes that are tilted with height (e.g., Zhang and Webster 1989; Yang et al. 2007a, 2011, 2012). Regions of active/inactive convection are also determined by the dynamics of the large-scale waves.

Across Africa and the Atlantic, the meridional shear in the zonal flow is much stronger than elsewhere in the tropics as a result of the AEJ. Therefore, the structures of any equatorially trapped large-scale waves must overlap with regions of strong shear. Although equatorially trapped waves obtained as normal mode solutions to the shallow-water equations on a uniform flow 

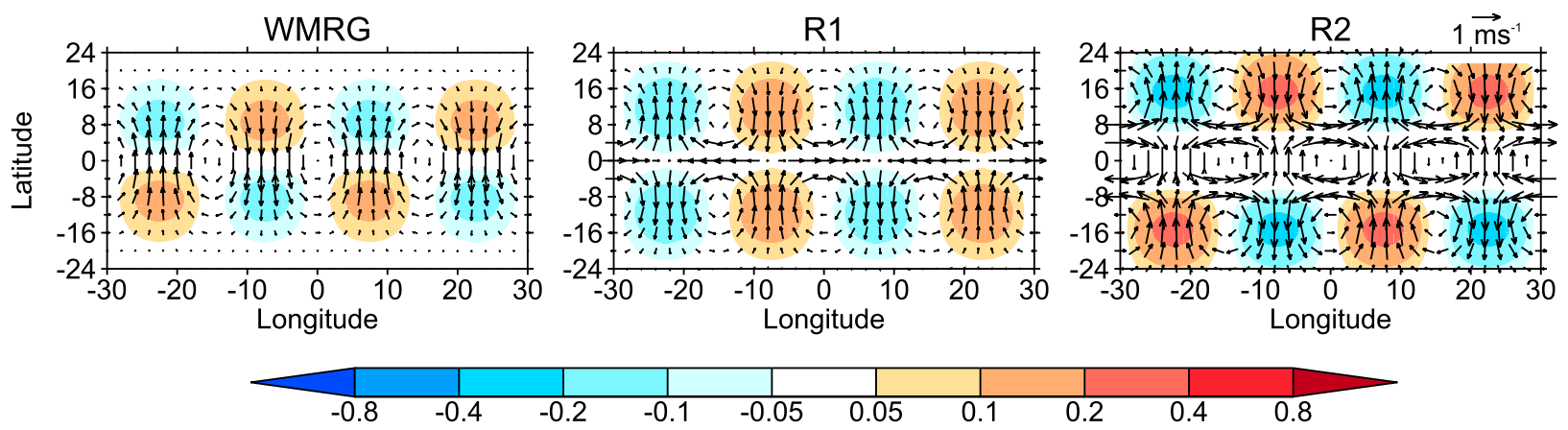

FIG. 1. The horizontal structures of the normal modes for a resting atmosphere. The $n=0$ westward-moving mixed Rossby-gravity (WMRG) and the $n=1$ and 2 westward-moving Rossby (R1 and R2) waves. Vectors indicate horizontal winds and colors divergence $\left(\times 10^{-6} \mathrm{~s}^{-1}\right)$. The meridional trapping scale $y_{0}$ has been taken to be $6^{\circ}$ and the zonal wavenumber $k=12$.

are untilted, orthogonal, and noninteracting, these properties are lost in the presence of shear in the zonal flow. Vertical wind shear also enables interaction between Rossby and gravity waves, as shown for example in a two-layer model by Sakai (1989). The aim of this study is to identify interactions between AEWs and equatorially trapped waves and their effects on AEW variability. A particular focus is on AEW interaction with WMRG wave activity propagating along the equator and excitation of those waves by equivalent barotropic Rossby waves from the Southern Hemisphere.

The paper is organized as follows. Section 2 describes the reanalysis data and methods used for vorticity tracking, spatiotemporal filtering, spatial projection onto wave components, and the regression technique. Section 3 presents a climatology of the distribution of AEW intensity, both spatially, through tracking positive vorticity centers within AEWs, and also in zonal wavenumber-frequency space. The interannual variability is also examined. Section 4 presents a case study of AEWs occurring during the active 1995 summer season and the associated tropical cyclogenesis events. Reanalysis data are projected onto the horizontal structures of equatorial wave components (on pressure levels spanning the troposphere) and the link between westward-propagating wave structures and the vorticity centers of AEWs is examined in detail. In section 5, the case study findings are extended to the entire reanalysis period by calculating average horizontal and vertical structures relative to the AEW vorticity centers using a lag regression analysis. Section 6 examines the differences in equatorial wave activity and the seasonal-mean flow between years of strong and weak AEW activity. Dynamical mechanisms linking the different waves are identified using the theory for wave propagation on the observed seasonal-mean flow. Conclusions are drawn in section 7

\section{Data and methodology}

\section{a. Data}

The data used in this study are from the European Centre for Medium-Range Weather Forecasts interim reanalysis (ERA-Interim; data available from ECMWF; Dee et al. 2011). The fields used are the horizontal winds $(u, v)$ and the geopotential height $(Z)$ for the period from 1979 to 2010 . The fields are available 6-hourly with horizontal resolution of about $0.7^{\circ}$ and at 37 pressure levels from 1000 to $1 \mathrm{hPa}$. The proxy used for tropical convection is NOAA interpolated daily outgoing longwave radiation (OLR) for the period from 1979 to 2010 (Liebmann and Smith 1996).

The troughs of AEWs can be tracked by identifying their characteristic positive vorticity centers at the level of the AEJ $(600 \mathrm{hPa})$. In this study, the vorticity centers are tracked using the methodology of Thorncroft and Hodges (2001) and Hopsch et al. (2007). The vorticity field used is spectrally filtered, where the total wavenumbers equal or smaller than 5 are removed and the field is truncated to T42 and the spectral coefficients tapered to suppress Gibbs oscillations. The tracks of positive vorticity centers at $600 \mathrm{hPa}$ with amplitude larger than $0.5 \times 10^{-5} \mathrm{~s}^{-1}$ are used to represent the phase propagation of AEWs.

\section{b. Basic equatorial wave theory and identification of equatorial waves from data}

Following Matsuno (1966) and Gill (1980, 1982), equatorial wave theory is based on linearization about a resting atmosphere and separation of the vertical structure from that in the horizontal. The horizontal and temporal behavior of the $u, v$, and $Z$ satisfy the linearized shallow-water equations with gravity wave speed $c$, the separation constant from the vertical structure equation that can also satisfy relevant surface and upper boundary conditions. This is possible only for discrete 
values of the separation constant, $c_{e}=N H / m \pi$, where $m$ is the vertical mode number, $H$ is the height of the tropopause, $N$ is the buoyancy frequency, and it is assumed that the tropopause acts as a rigid lid.

For the horizontal equations, the representation of $u, v$, and $Z$ fields are of the form

$$
(u, v, Z)=[U(y), V(y), Z(y)] \exp [i(k x-\omega t)],
$$

where $k$ is the zonal wavenumber and $\omega$ is the frequency. The equatorial wave solutions are most easily formulated in terms of new variables, $q, r$, and $v$ (Gill 1980), where

$$
q=g Z / c_{e}+u \text { and } r=g Z / c_{e}-u .
$$

There is the Kelvin wave solution with zero $v$ and $\omega=k / c_{e}$, and there are solutions with nonzero $v$ with the dispersion relation:

$\frac{\omega^{2}}{c_{e} \beta}-c_{e} \frac{k}{\omega}-\frac{c_{e}}{\beta} k^{2}=(2 n+1), \quad$ for $\quad n=0,1,2 \ldots$,

where $n$ is the meridional mode number and $\beta$ is $\partial f / \partial y$. Since the Kelvin wave satisfies this relation with $n=-1$, this notation is conventionally used to label it. The Kelvin wave is eastward moving. The $n=0$ mode is the mixed Rossby-gravity (MRG) wave that has both eastward (EMRG) and westward-moving (WMRG) solutions. For $n=1$ and higher there are westwardmoving equatorial Rossby waves and both eastwardand westward-moving gravity wave solutions.

The meridional $(y)$ structures of the waves satisfying the shallow-water equations on the equatorial $\beta$ plane are parabolic cylinder functions:

$$
\begin{aligned}
D_{n}\left(\frac{y}{y_{0}}\right) & =\exp \left[-\frac{1}{4}\left(\frac{y}{y_{0}}\right)^{2}\right] P_{n}\left(\frac{y}{\sqrt{2} y_{0}}\right), \\
\text { where } y_{0} & =\left(c_{e} / 2 \beta\right)^{1 / 2},
\end{aligned}
$$

is the meridional scale, $P_{n}$ is proportional to a Hermite polynomial of order $n$, and the waves are trapped at the equator on a scale $y_{t}=(2)^{1 / 2} y_{0}$.

Although the separation of the vertical and horizontal structures is possible for a resting atmosphere, in general the separation of variables for observed atmospheric disturbances is not possible because of shear in the zonal flow and the lack of rigid lid so that analysis in terms of vertical modes and horizontal wave structures is not strictly valid. Hence, in Yang et al. (2003) a methodology to identify equatorially trapped waves in observational data was developed. In this study, no assumption about the vertical structure or dispersion relation is made, but at each level the fields in the tropics are projected onto the different equatorial wave modes using their horizontal structures described by parabolic cylinder functions in $y$ and sinusoidal variation in $x$.

Guided by basic equatorial wave theory, the parabolic cylinder function expansions are organized and described as follows:

$$
\begin{aligned}
& q=q_{0} D_{0}+q_{1} D_{1}+\sum_{n=1}^{n=\infty} q_{n+1} D_{n+1} \\
& v=0+v_{0} D_{0}+\sum_{n=1}^{n=\infty} v_{n} D_{n} \\
& r=0+0+\sum_{n=1}^{n=\infty} r_{n-1} D_{n-1} \\
& \begin{array}{lll}
\uparrow & \uparrow & \uparrow
\end{array} \\
& n=-1 \quad n=0 \quad n=1,2 \ldots
\end{aligned}
$$

These functions form a complete and orthogonal basis, and the projections in Eq. (6) are quite general, with $q_{0} D_{0}$ describing the Kelvin wave; $q_{1} D_{1}$ and $v_{0} D_{0}$ describing $n=0$ MRG waves; and $q_{n+1} D_{n+1}, v_{\mathrm{n}} D_{n}$, and $r_{n-1} D_{n-1}$ describing $n \geq 1$ equatorial Rossby waves or gravity waves. The theoretical horizontal structures of equatorial waves have been shown in a number of previous studies (e.g., Matsuno 1966; Takayabu 1994; Wheeler et al. 2000; Yang et al. 2003). The horizontal winds and divergence of the WMRG, R1, and R2 waves that are relevant to this study are illustrated in Fig. 1.

It is often convenient to identify the components of the projection with their resting atmosphere labels, but it is not assumed that these are normal modes of the system. In particular, different wave components may together make up an observed structure and their relative amplitudes may vary in time. For example, if a strong wave in vorticity exists at $10^{\circ}-15^{\circ} \mathrm{N}$ (typical for an AEW) but there is no disturbance in the $\mathrm{SH}$ at the same level, then this would project strongly onto a combination of R1 and R2 in phase in the Northern Hemisphere $(\mathrm{NH})$. The two structures would then approximately cancel in the $\mathrm{SH}$ in both vorticity and divergence (as seen from Fig. 1). This does not imply that these structures evolve just as R1 and R2 modes would on a uniform flow-indeed the AEW exists in the strongly sheared environment of the AEJ. However, as a basis the structures are useful because $u, v$, and $Z$ are consistent with propagating wave features (albeit only exact solutions in the absence of wind shear). If a strong projection of tropical winds onto an equatorially trapped wave structure is found (as will be shown for WMRG waves), further work is required to establish whether or not this structure propagates coherently in the fashion predicted, at least qualitatively, by equatorial wave theory. 
This horizontal projection technique, applied on each level independently, has been successfully employed in a number of previous observational studies for convectively coupled equatorial waves (Yang et al. 2007a,b,c), equatorial wave behaviors in different QBO phases (Yang et al. 2011, 2012) and different ENSO phases (Yang and Hoskins 2013, 2016), and has been used to validate model simulations of equatorial waves (Yang et al. 2009).

\section{c. Statistical analysis procedures}

In this study, the projection methodology described above will be used to identify equatorial waves and then connect them with AEWs using a linear regression technique. In detail the analysis method is described as follows.

\section{1) Filter data in the WAVEnUmber AND FREQUENCY DOMAIN}

Before projection onto the equatorial structure basis, the dynamical fields $v, q$, and $r$ between $24^{\circ} \mathrm{N}$ and $24^{\circ} \mathrm{S}$ in the global tropical belt are separated into eastwardand westward-moving components using a space-time spectral analysis that transforms data from the $x-t$ domain into the $k-\omega$ domain by performing 2D FFT in the zonal and time direction (Hayashi 1982). The data are filtered using a broad spectral domain with zonal wavenumber $-40<k<-3$ and period of $2.5-10$ days to define the westward-moving components. Note that the convention chosen here is that $\omega \geq 0$ but $k$ is positive for eastward and negative for westward phase speeds (see Fig. 3). This filtering domain is wider than the 3-5- or 2-6-day filter used in many other studies of AEWs. The lower cutoff of 2.5 days removes the diurnal cycle, and the upper cutoff of 10 days is aimed to remove intraseasonal variability. There is a gap in power spectra between periods of 10 and 20 days and other authors have used this to partition propagating equatorial waves from the Madden-Julian oscillation [e.g., Schreck et al. (2012) used an upper cutoff of 17 days].

\section{2) PROJeCT WESTWARD-FILTERED COMPONENTS ONTO HORIZONTAL STRUCTURES OF EQUATORIAL WAVES}

The Fourier coefficients [e.g., $V(y)$ for each $k$ and $\omega$ ] of westward-moving $v, q$, and $r$ are separately projected onto parabolic cylinder functions as in Eq. (6) to obtain equatorial wave modes. To do this it is necessary to first specify the meridional scale $y_{0}$ (or equivalently the trapping scale $y_{t}$ ) and hence the speed $c_{e}$, so that $q$ and $r$ can be formed from $u$ and $Z$ according to Eq. (2). As in previous studies (e.g., Yang et al. 2003, 2007a,b,c, 2012), $y_{0}=6^{\circ}$ (trapping scale $y_{t} \approx 8.4^{\circ}$ ) is used. The value of $y_{0}$ is determined from a best fit to the data, although it is found that the analysis is not sensitive to the particular value of chosen $y_{0}$ (Yang et al. 2003, 2012). From Eq. (5), $c_{e}$ is determined to be about $20 \mathrm{~m} \mathrm{~s}^{-1}$. This $c_{e}$ is used only to create the new dependent variables $q$ and $r$ from $u$ and $Z$ and later to reverse the variable transform.

\section{3) TRANSFORM THE FOURIER COEFFICIENTS FOR EACH WAVE MODE BACK INTO PHYSICAL SPACE}

The projected $n=0,1$, and 2 components will be referred to as WMRG, R1, and R2 waves, respectively. Note that although the winds are broadband-filtered before projection (for each $k$ and $n$ ) the fields obtained by the inverse transform capture variation in wave component amplitude with longitude because the range in zonal wavenumber is broad.

\section{4) REgRESSING WAVES ONTO AEW VORTICITY CENTERS}

To investigate the relationship between equatorial waves and AEWs, linear regression techniques similar to those developed in Yang et al. (2007a,b) are used to regress the horizontal winds of the westward-moving equatorial waves onto vorticity centers tracked at $600 \mathrm{hPa}$ across West Africa and the tropical North Atlantic. The regression is based on considering the horizontal fields in a frame where the longitude coordinate is expressed relative to the position of each positive vorticity center tracked through a region. More specifically, in the regression the independent variable is the value of the tracked vorticity at the location of the maximum falling anywhere within a specified region (e.g., $5^{\circ}-15^{\circ} \mathrm{N}$, $7.5^{\circ} \mathrm{W}-7.5^{\circ} \mathrm{E}$ and as shown in Fig. 2a). The horizontal wind fields (westward-filtered components or the projected equatorial waves) are the dependent variables. The wind fields at each latitude and at each level are regressed onto the positive vorticity centers in a given longitude sector. The regression yields a separate regression equation for each grid point (in the featurerelative frame). The linear dependence of the wind fields can then be mapped by applying the regression equation for each grid point. The regression can also be performed by applying a lag to the dependent variables (wind fields) relative to the independent variable (central vorticity) to investigate the time evolution of waves and their zonal propagation. The regression is performed over all 32 June-September (JJAS) seasons concatenated to obtain the climatology of the wave behavior in section 5. It is also performed over six strong and six weak AEW seasons for strong and weak AEW cases, to examine their differences in section 6 . The Student's $t$ test is used to test the statistical significance for regression coefficients and difference fields between 

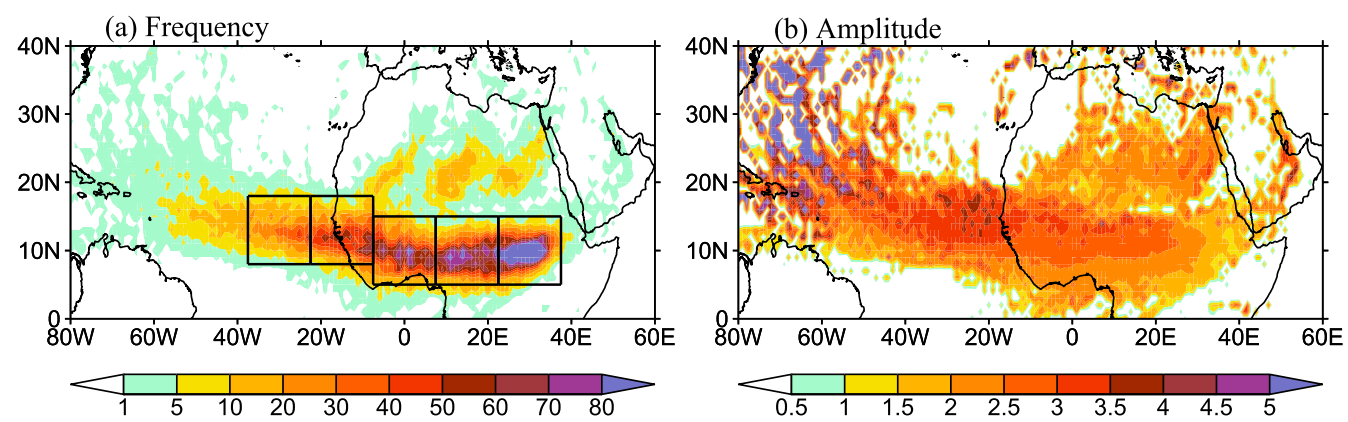

(c) Amplitude anomaly

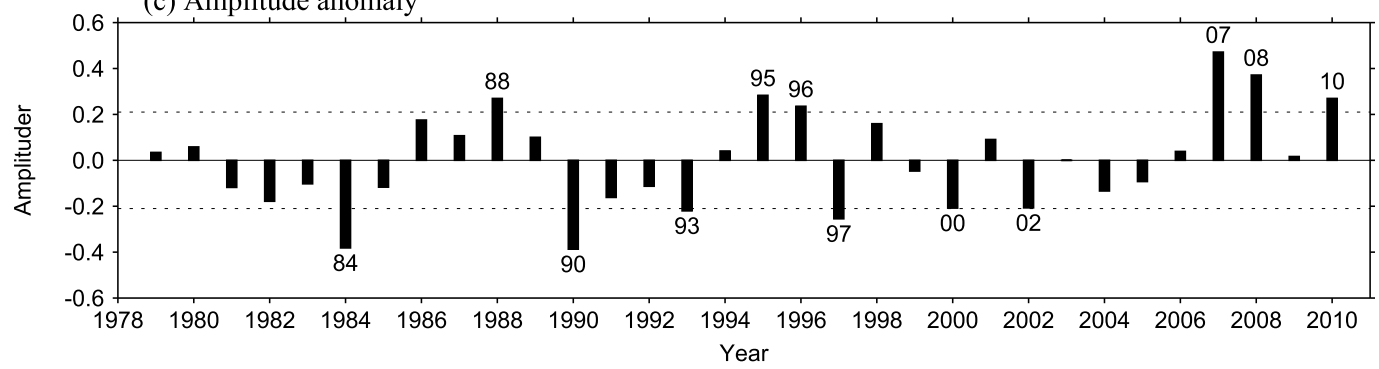

FIG. 2. Statistics of all tracked vorticity centers at $600 \mathrm{hPa}$, passing through the region $5^{\circ}-20^{\circ} \mathrm{N}, 10^{\circ} \mathrm{W}-35^{\circ} \mathrm{E}$ in June-September of 1979-2010. (a) Frequency (total occurrence numbers) and (b) mean amplitude $\left(\times 10^{-5} \mathrm{~s}^{-1}\right)$ of positive vorticity centers. The boxes indicate five regions that will be used for regression. Each region spans $15^{\circ}$ in longitude, centered at $30^{\circ} \mathrm{W}, 15^{\circ} \mathrm{W}, 0^{\circ}, 15^{\circ} \mathrm{E}$, and $30^{\circ} \mathrm{E}$, and $10^{\circ}$ in latitude, $8^{\circ}-18^{\circ} \mathrm{N}$ for the two west regions and $5^{\circ}-15^{\circ} \mathrm{N}$ for the three east regions. (c) Time series of the amplitude anomaly of the vorticity centers within all five regions in 1979-2010. Two dotted lines indicate one standard deviation range. There are 6 years with amplitude anomalies larger than one standard deviation: 1988, 1995, 1996, 2007, 2008, and 2010, and 6 weak years with amplitude anomaly smaller than one standard deviation: 1984, 1990, 1993, 1997, 2000, and 2002.

strong and weak AEW years. The significance level of $95 \%$ is used in all relevant figures.

\section{Climatology of AEWs and equatorial wave variability}

Figures $2 \mathrm{a}, \mathrm{b}$ show the geographic distribution of frequency (occurrence) and amplitude of positive vorticity centers tracked at $600 \mathrm{hPa}$, passing through $5^{\circ}-20^{\circ} \mathrm{N}$ and $35^{\circ} \mathrm{E}-10^{\circ} \mathrm{W}$ in JJAS $1979-2010$. It is seen the density is farther equatorward over the African continent than across the Atlantic. The low-latitude range of occurrence of AEWs provides a potential link between AEWs and westward-moving equatorially trapped waves. The vorticity centers that propagate to the extratropics with stronger amplitude (Fig. 2b) are recurving tropical storms; however, their occurrence frequency is much lower. The area where AEWs are most prevalent is divided into five regions, each spanning $15^{\circ}$ longitude and $10^{\circ}$ latitude, as indicated by the boxes in Fig. 2a. They will be used in sections 5 and 6 for the regression onto vorticity centers passing through each region.

Analysis of the AEW tracks indicates that there is a clear interannual variability, both in the frequency and intensity, of the vorticity centers of AEWs. Figure 2c shows the time series of amplitude anomaly of vorticity centers averaged over the five regions, where six strong and six weak AEW years are identified according to the amplitude being stronger or weaker than one standard deviation. The $6 \mathrm{yr}$ with the strongest and the weakest AEWs are labeled and these are used to create composites in section 6 .

To examine the overall variability of tropical disturbances over the North African and Atlantic sector $\left(75^{\circ} \mathrm{W}-\right.$ $45^{\circ} \mathrm{E}$ ) in JJAS, space-time power spectra (Hayashi 1982) of meridional winds are calculated. This is done at each latitude and then averaged over $5^{\circ}-18^{\circ} \mathrm{N}$. The zonal and temporal Fourier transforms are performed on data from a limited $120^{\circ}$ zonal sector and 122-day time windows. Prior to applying fast Fourier transforms, the zonal average in the $120^{\circ}$ sector and time mean over the 122 days are removed and the values are tapered to zero at each end of the zonal sector and time window. The minimum zonal wavenumber that can be determined from data in a $120^{\circ}$ sector is $k=3$ (and spectral coefficients are obtained only for its harmonics $k=3,6,9, \ldots$ ). Figure 3 shows the power spectra of $v$ at 200 and $700 \mathrm{hPa}$ in the $75^{\circ} \mathrm{W}-45^{\circ} \mathrm{E}$ sector, averaged for all 32 JJAS seasons in 1979-2010. It can be 
(a) $200 \mathrm{hPa}$

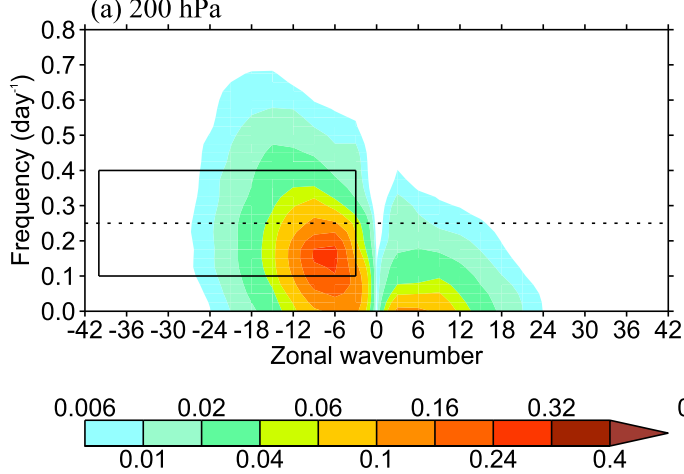

(b) $700 \mathrm{hPa}$

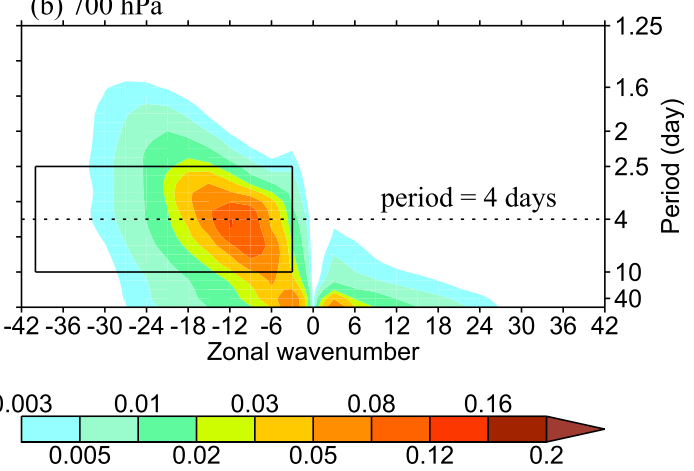

FIG. 3. Zonal wavenumber-frequency power spectra of meridional wind $v$ at $5^{\circ}-18^{\circ} \mathrm{N}$ in the African-Atlantic sector $\left(75^{\circ} \mathrm{W}-45^{\circ} \mathrm{E}\right)$ in June-September averaged over 1979-2010: (a) 200 and (b) $700 \mathrm{hPa}$. The box indicates the broadband-filter domain used in this study and the dotted line indicates a period of 4 days.

seen that at both pressure levels, the westward-moving (indicated by $k<0$ ) power dominates. The strongest power at $700 \mathrm{hPa}$ is clearly coincident with that of typical AEWs with $k \approx 9-15$ and a period of $\sim 3-6$ days. On the other hand, the strongest power at $200 \mathrm{hPa}$ shows smaller wavenumbers and longer periods than those of AEWs. The box indicates the broad filter domain that is used in this study (see section 2c).

Figure 4 shows the geographic distribution of variance in westward-moving disturbances and equatorial waves. Longitude-height cross sections depict the standard deviations (SD; daily departure from monthly mean) in meridional wind for westward-filtered components at $12^{\circ} \mathrm{N}, 0^{\circ}$, and $12^{\circ} \mathrm{S}$ (Figs. $4 \mathrm{a}-\mathrm{c}$ ) averaged over 32 JJAS seasons. The projection of meridional wind on to the WMRG wave component is shown at the equator (Fig. 4d). Note that for WMRG waves, because their horizontal structures are untilted, the standard deviation structure shown is independent of the latitude chosen and only the amplitude changes. As expected, at $12^{\circ} \mathrm{N}$ where AEWs are prevalent, there is a $\mathrm{SD}(v)$ maximum in the lower troposphere over West Africa and the east Atlantic $\left(40^{\circ} \mathrm{W}-30^{\circ} \mathrm{E}\right)$. It is clear that this low-level feature also occurs for $\operatorname{SD}(v)$ at $0^{\circ}$ and for the WMRG wave. It is interesting that in the upper troposphere there is also a maximum $\mathrm{SD}(v)$ in the same longitude sector both in the SH (Fig. 4c) and on the equator (Fig. 4b), but not in the NH (Fig. 4a). The uppertropospheric maximum also appears for WMRG waves in the sector. The link between wave activity in the $\mathrm{SH}$ and AEWs over West Africa will be explored in section 6 .

\section{Case study of AEWs in 1995 and relation to tropical cyclogenesis}

To examine the connection between AEW vorticity centers and propagating WMRG waves, the 1995 season is investigated in detail including a particular tropical storm that occurred in this season. The 1995 summer was a highly active Atlantic hurricane season that produced 21 tropical cyclones, 19 named storms, as well as 11 hurricanes including 5 major hurricanes. Figure 5a shows the Hovmöller plot of the 600-hPa vorticity tracks passing through $35^{\circ} \mathrm{E}-10^{\circ} \mathrm{W}$ in JJAS 1995 , with vorticity centers in $5^{\circ}-20^{\circ} \mathrm{N}$ indicated by circles. Colors indicate intensity and those leaving the tropics are indicated by gray circles. It shows that the amplitude of vorticity tracks in the Atlantic region is generally stronger than that over the African continent. Figure 5b shows the corresponding Hovmöller plot for the meridional wind of the WMRG waves at $700 \mathrm{hPa}$, with the vorticity tracks superimposed. It is striking that the westward phase speed of the WMRG waves varies little and is faster than the westward motion of the majority of vorticity centers. Furthermore, there are five periods where there is a distinct eastward group velocity of WMRG waves over the Atlantic to about $10^{\circ} \mathrm{E}$. A particularly marked episode begins in mid-July from the western Atlantic. This group behavior is predicted by equatorial wave theory for WMRG waves (explored further in section 6) and is evidence that the WMRG structures identified by the projection technique are exhibiting mode-like behavior that is independent of the vorticity centers within the AEWs.

As a case study, the development of a category-4 hurricane, named "Felix" is examined (indicated by the letter F in Fig. 5). It was reported that on 6 August, an AEW vorticity center crossed the west coast of Africa and quickly developed into Tropical Storm Felix on 8 August, and then became a category- 4 hurricane on 12 August. The vorticity track in the first half of August, shown in Fig. 5a, demonstrates this event. Figure 6 a shows the vorticity centers and westward-filtered 
(a) $v$ at $12^{\circ} \mathrm{N}$

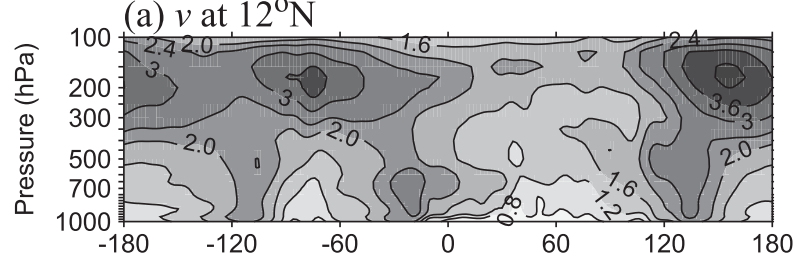

(b) $v$ at $0^{\circ} \mathrm{N}$
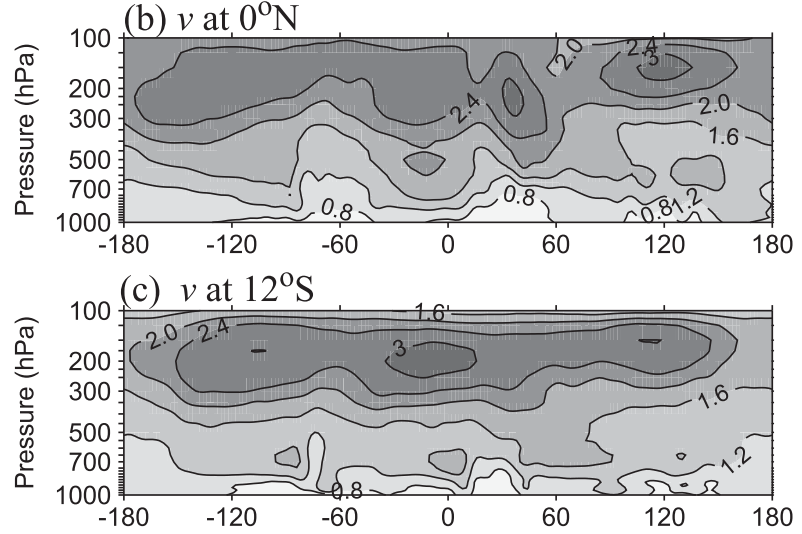

(d) WMRG at $0^{\circ} \mathrm{N}$

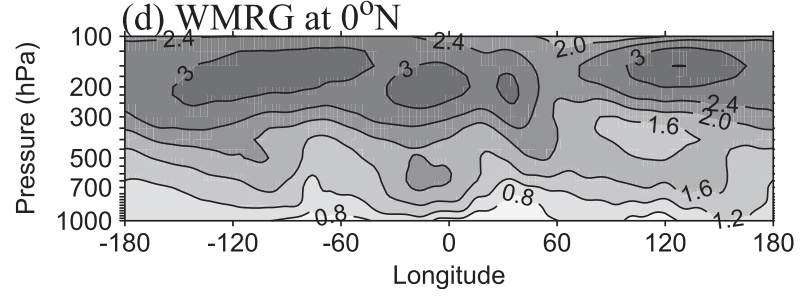

FIG. 4. Longitude-height cross sections of standard deviations averaged over JJAS 1979-2010 for the westward-filtered meridional wind $v\left(\mathrm{~m} \mathrm{~s}^{-1}\right)$, at (a) $12^{\circ} \mathrm{N}$, (b) $0^{\circ}$, and (c) $12^{\circ} \mathrm{S}$. (d) The projection of $v$ onto WMRG structures at $0^{\circ}$.

horizontal winds at $700 \mathrm{hPa}$ during 4-9 August. On 4 August, there is a positive vorticity center over West Africa, indicated by the letter A. This moves westward and intensifies over the Atlantic, indicating the development of Tropical Storm Felix. The development of A is associated with strong cross-equatorial flow that propagates westward with the center $\mathrm{A}$ and projects strongly onto a WMRG wave structure (Fig. 6b). On 4 August, A begins in the trough (positive vorticity maximum) of the WMRG wave. Over 5-7 August, the WMRG wave moves faster to the west, until $\mathrm{A}$ is in phase with the strong northward cross-equatorial flow associated with the WMRG wave. On 8 August, the WMRG wave weakens in the west but intensifies in the east because of its eastward group velocity (wave packet moving eastward). A new vorticity center, "B," intensifies in the convergent region just west of the strongest lower-tropospheric cross-equatorial flow of the WMRG wave. It is noted that in this case study, the WMRG has a zonal wavelength of about $60^{\circ}(k=6, \sim 6700 \mathrm{~km})$, longer than that of the AEW wavelength of $40^{\circ}(k=9)$ estimated by the separation of centers $\mathrm{A}$ and $\mathrm{B}$.

Figure 7 shows that in the early stages of intensification, 5-7 August, A is also connected to crossequatorial meridional wind in the upper troposphere (Fig. 7a), which again projects strongly onto the WMRG wave (Fig. 7b). The cross-equatorial flow has opposite sign to that at $700 \mathrm{hPa}$, with maximum divergence immediately to the east of A during 5-7 August. Upperlevel divergence is in a suitable position for the development of the low-level positive vorticity center by vorticity stretching (as will be shown in section 6) and it is hypothesized that the WMRG wave may play an important role in the intensification of the vorticity center and its development into tropical storm category. On 8 August, vorticity center B appears where the meridional wind is weak in the upper troposphere and B does not intensify into a strong storm. It is also noted that on 9 August another vorticity center $\mathrm{C}$ grows to the east of $\mathrm{B}$ and in this case intensifies beneath the upper-level divergence of the WMRG wave, just as center A did.

Another interesting feature to note is that in Fig. 7a there is a Rossby wave train in the $\mathrm{SH}$, indicated by the pattern of cyclonic and anticyclonic circulations centered near $12^{\circ} \mathrm{S}$ with a zonal wavenumber of about 5 . This pattern moves westward in step with the large-scale cross-equatorial flow of the WMRG structure. The importance of SH equivalent barotropic Rossby waves (RWs) is explored in section 6.

The case study indicates that WMRG waves are involved in the development of Tropical Storm Felix. Although the WMRG wave has a much longer wavelength than the separation of centers $\mathrm{A}$ and $\mathrm{B}$, and moves faster to the west, these vorticity centers amplify when the WMRG wave is in a particular phase with the cross-equatorial flow maximum just to the east of the vorticity center at the AEJ level.

It should be pointed out that although $u$ and $v$ are independently projected onto each wave mode without supposing a theoretical relationship between them, the projected $(u, v)$ for the $n=0$ waves (Figs. 6b, 7b) show coherent WMRG wave structures over the whole wave phase. This indicates the robustness in the methodology of identifying equatorial wave modes through projection.

\section{Average wave structures associated with AEWs calculated by regression onto vorticity centers}

To examine the climatology of wave structures associated with AEWs and to explore whether the conclusions from the 1995 case study are representative of the 
(a)

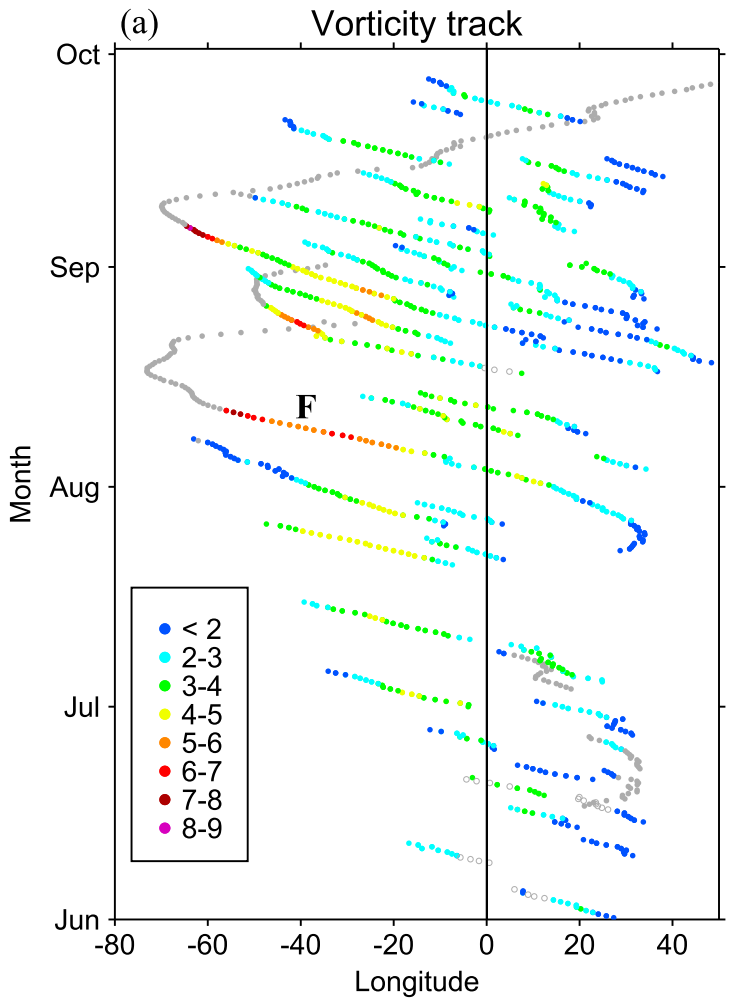

(b)

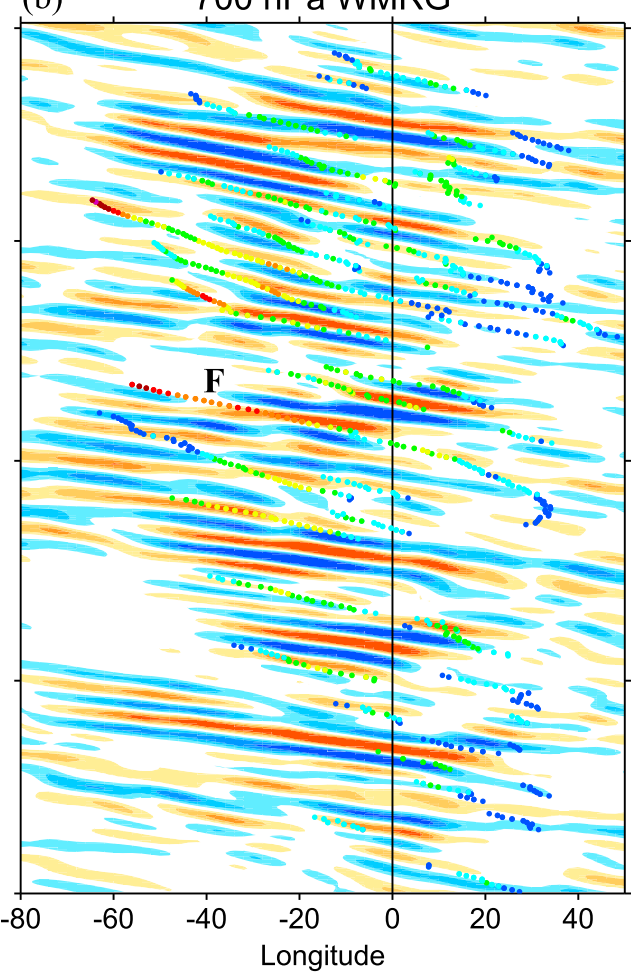



FIG. 5. (a) Vorticity tracks at $600 \mathrm{hPa}$ in JJAS 1995 , with vorticity centers at $5^{\circ}-20^{\circ} \mathrm{N}$ indicated by colored circles (color scales show intensity in $10^{-5} \mathrm{~s}^{-1}$ ) and outside of it indicated by gray circles. (b) The 700-hPa WMRG $v\left(\mathrm{~m} \mathrm{~s}^{-1}\right)$ at $0^{\circ}$ with vorticity centers at $5^{\circ}-20^{\circ} \mathrm{N}$ superimposed. The letter $\mathrm{F}$ in each panel indicates Hurricane Felix.

general situation, the regression technique described in section $2 \mathrm{c}$ is used to regress westward-filtered fields and the WMRG wave wind component onto the vorticity value at the tracked centers within AEWs. The regression is performed using data from the five longitudinal sectors (shown in Fig. 2a) for all 32 JJAS seasons spanned by ERA-Interim.

\section{a. Horizontal structures}

Figures 8 show the horizontal winds for the $700-\mathrm{hPa}$ westward-filtered winds, and the WMRG wave component at 700 and $200 \mathrm{hPa}$, regressed onto AEW positive vorticity centers in the region spanning $15^{\circ}$ longitude centered at $0^{\circ}$ (see Fig. 2a). The regression is calculated with a time lag of $-1,0$, and +1 days between the regressed field and vorticity center amplitude. The corresponding vorticity centers (red circles) are obtained by a self-regression of the centers as described in section $2 \mathrm{c}$. It is clear that coherent wave structures appear on either side of the vorticity centers. The westward-filtered component (Fig. 8a) shows a coherent wave train with the negative vorticity center to the west being stronger at lag -1 and the negative vorticity center to the east being stronger at lag +1 . This is consistent with an eastward group velocity. The WMRG waves (Figs. $8 \mathrm{~b}$ and $8 \mathrm{c}$ ) propagate faster to the west than the vorticity centers (as seen in the case study). In the lower troposphere, the vorticity center is located in the WMRG wave trough on day -1 but the vorticity center is more in phase with the southerly wind of the WMRG wave by day +1 . Since the AEW is off equatorial, the positive vorticity center is located within a region of convergence of the low-level northward flow in the WMRG wave. Furthermore, the WMRG negative vorticity center grows on the eastern flank, as in the full meridional wind, indicating that the observed eastward group velocity within the AEW is explained by the behavior of the WMRG wave component. Regression fields in the lower troposphere for the other four regions show similar structures and phase relationships. 

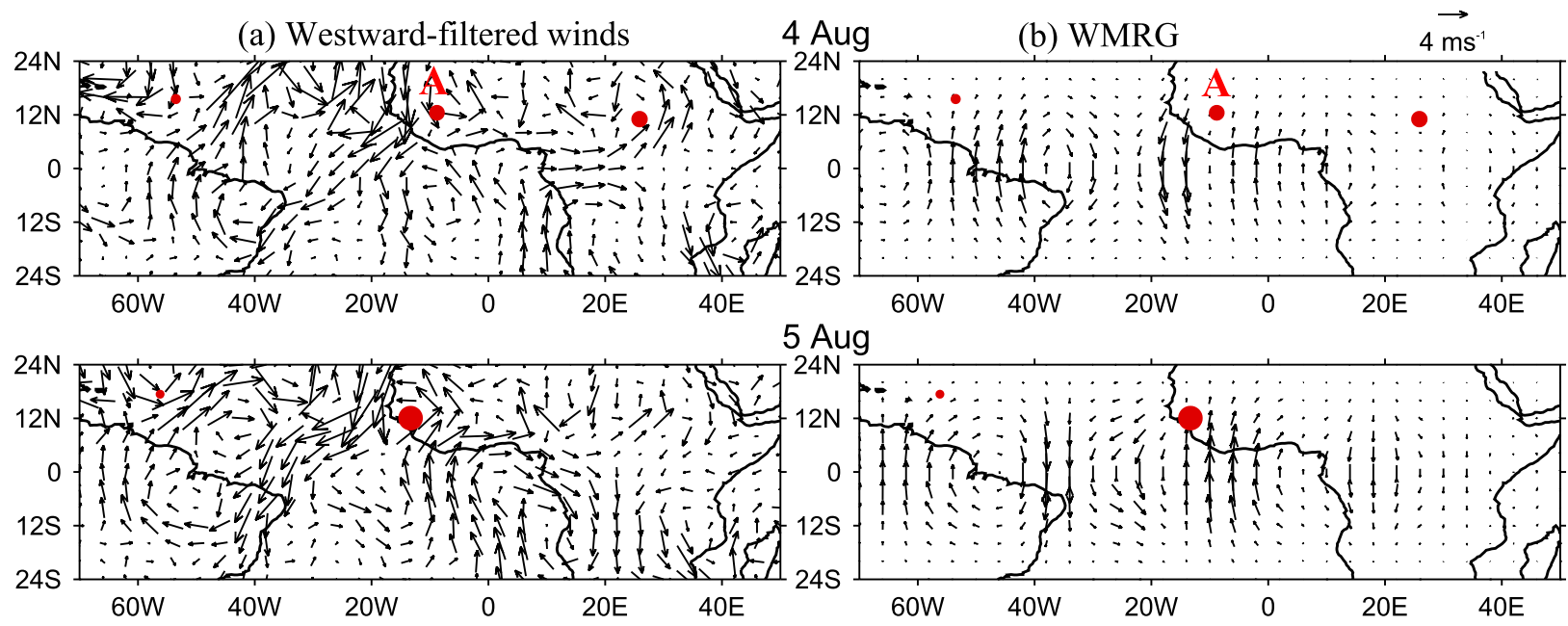

5 Aug
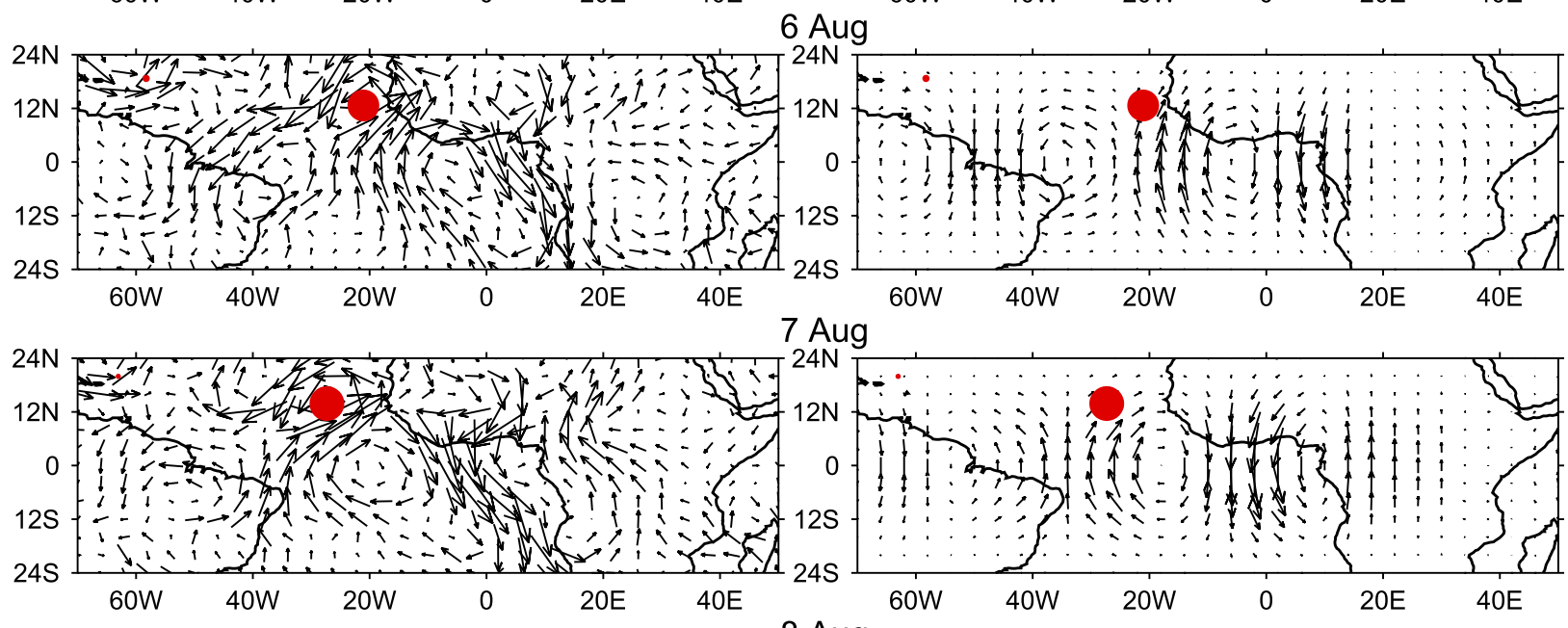

7 Aug
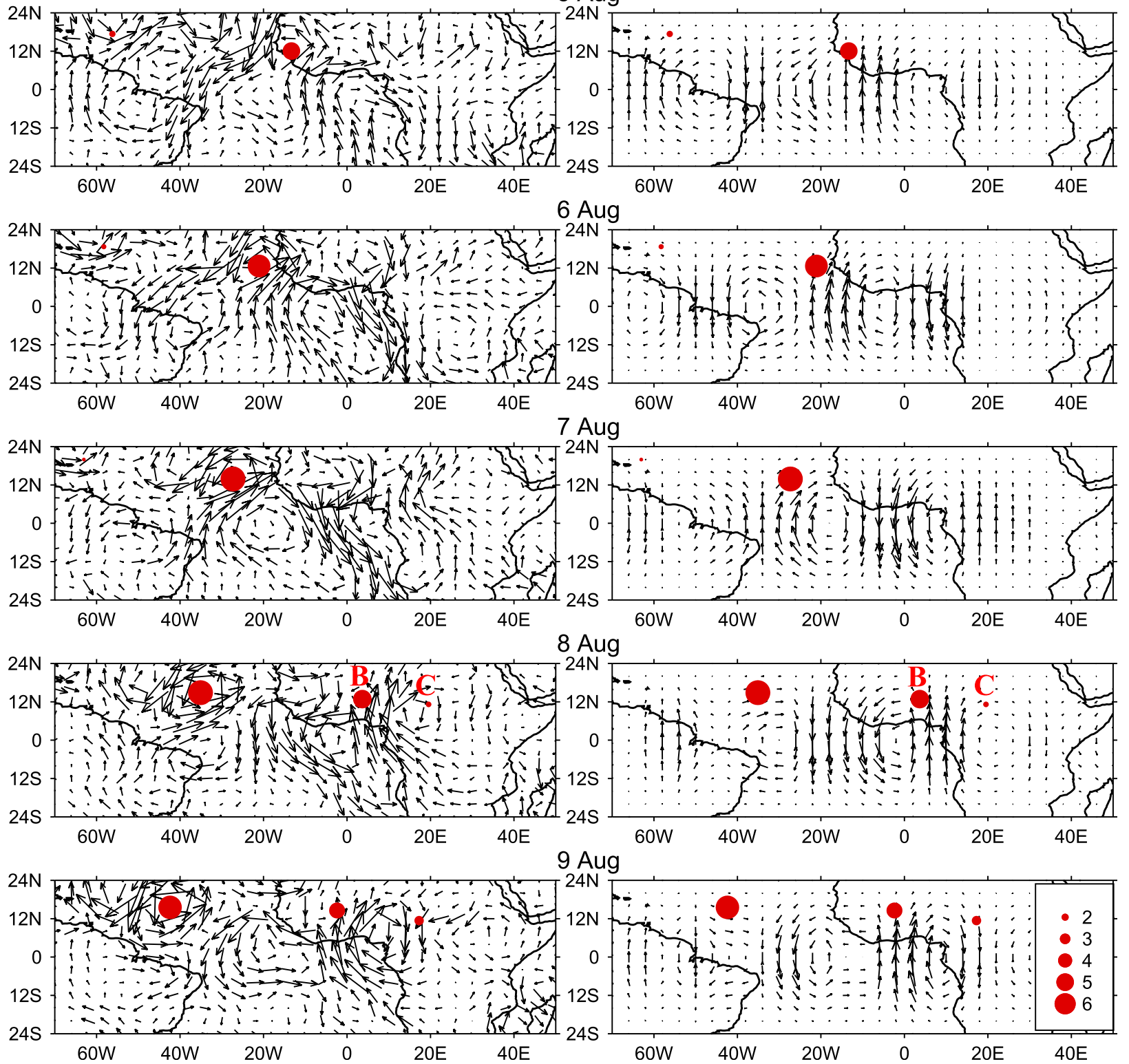

FIG. 6. Horizontal winds at $700 \mathrm{hPa}$, for (a) westward-filtered component and (b) the WMRG wave structure, during (top to bottom) 4-9 Aug 1995. The red circles indicate positive vorticity centers and are sized in accordance with the amplitude of the vorticity $\left(\times 10^{-5} \mathrm{~s}^{-1}\right)$. The letters A, B, and C indicate three vorticity centers.

In the upper troposphere, the WMRG wave (Fig. 8c) has its maximum southward wind in phase with the positive vorticity center at day -1 . The WMRG wave propagates faster to the west than the vorticity center at this level, too. Nevertheless, the regression shows that vorticity centers in AEWs intensify underneath 

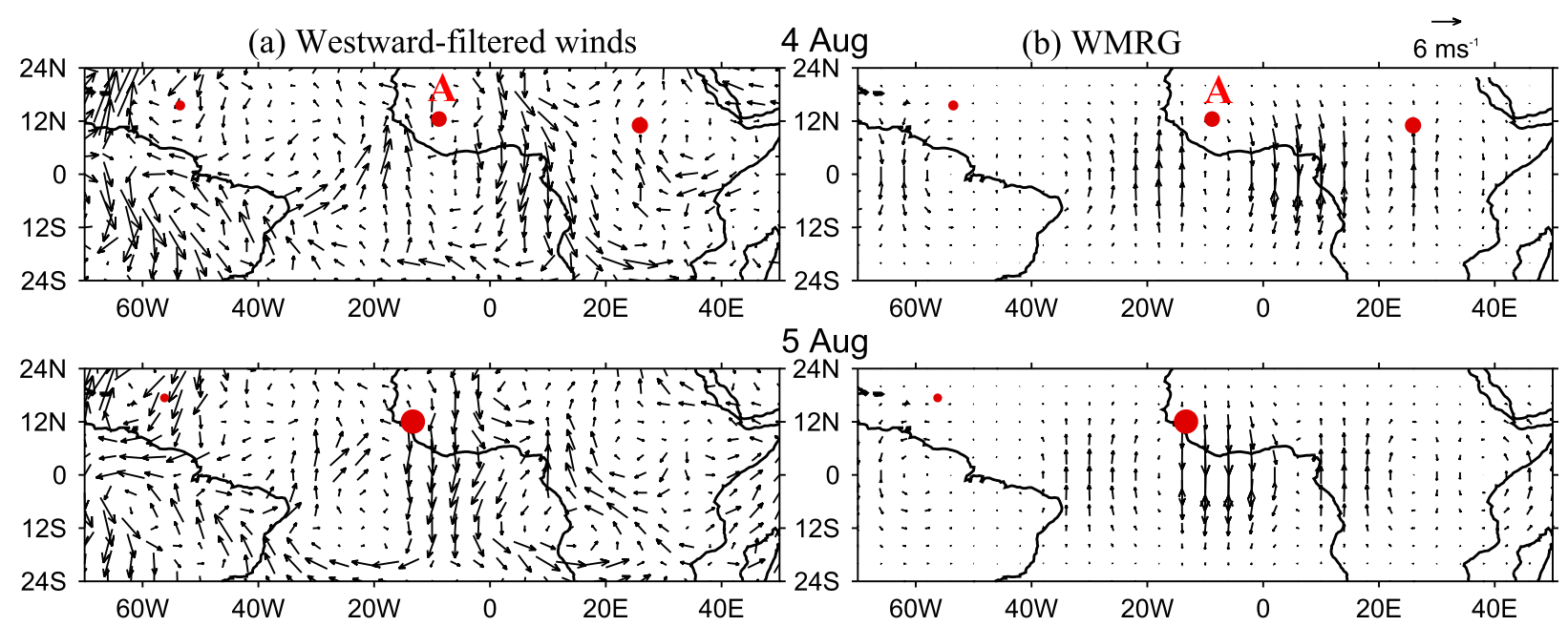

5 Aug

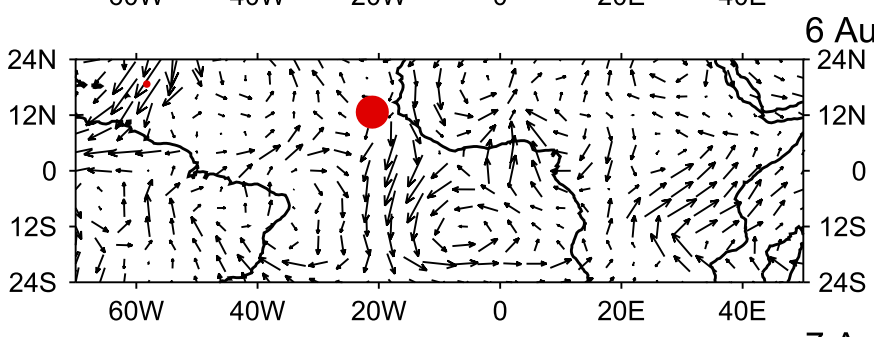

6 Aug


7 Aug


FIG. 7. As in Fig. 6, but for 200-hPa westward-filtered winds and WMRG waves.

divergence in the upper-tropospheric southward flow of the WMRG wave. Note also the westward displacement between the low-level convergence (immediately east of the vorticity center) and upper-level divergence (west of the center), which is examined in the next section. The climatology of regressed horizontal structures of WMRG waves and their relationship with AEWs are entirely consistent with those shown in the case study. 

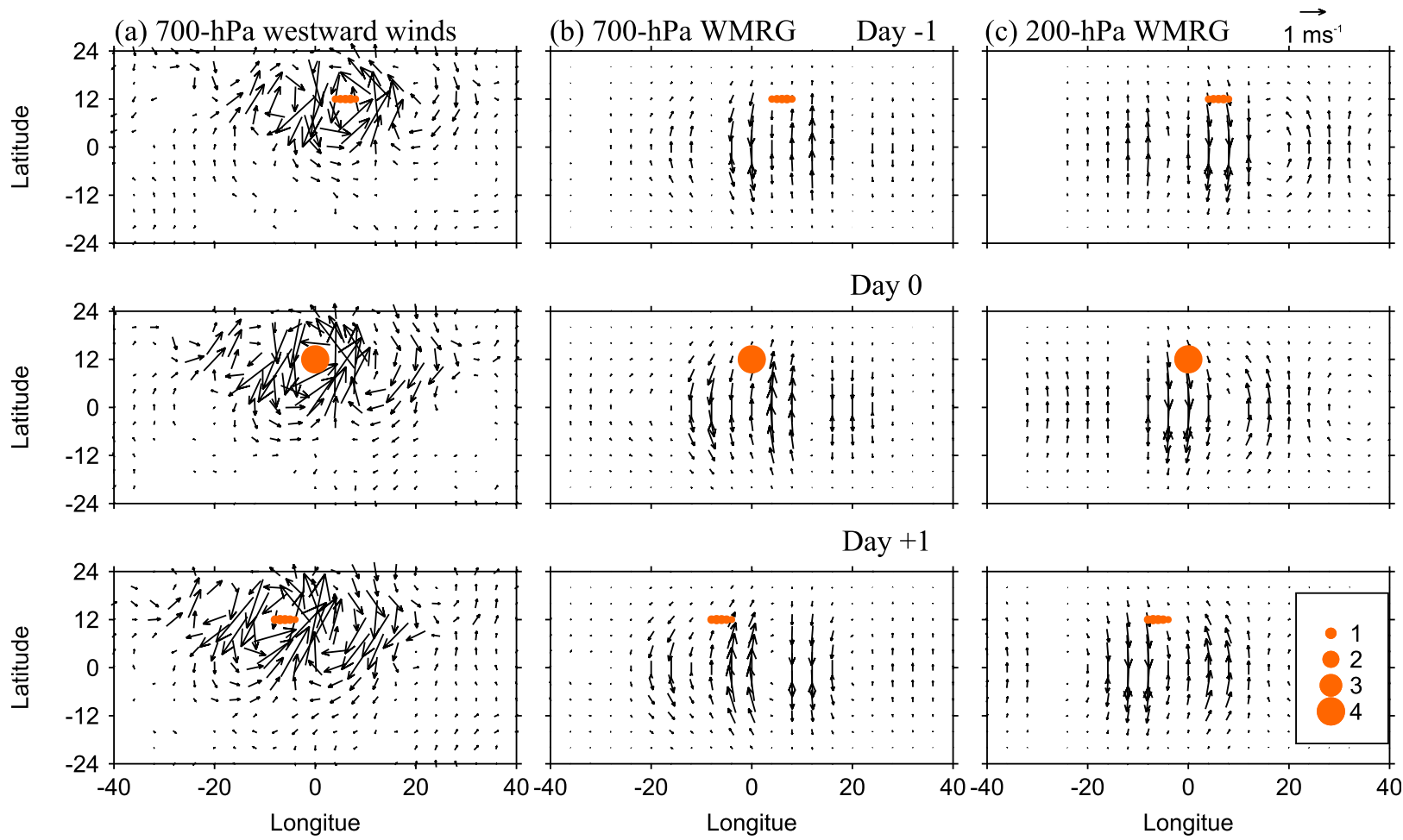

FIG. 8. Horizontal winds regressed onto vorticity centers in the region centered at $0^{\circ}$. (a) The 700 -hPa westward-filtered winds, (b) 700 -hPa WMRG waves, and (c) 200-hPa WMRG waves. The relative longitude axis is $0^{\circ}$ at the location of the positive AEW vorticity center. Red regions are autoregressed vorticity centers, sized in accordance with the amplitude of the vorticity with a unit of $10^{-5} \mathrm{~s}^{-1}$. Only those vectors with the $u$ or $v$ components exceeding the $95 \%$ significance level are shown.

\section{b. Vertical structure of the distinct wave types}

The regression of fields onto the value of vorticity at the AEW vorticity centers can be used to extract the vertical structure and tilt associated with the equatorial wave components because the regression is calculated on each pressure level independently as a function of longitude relative to the vorticity centers tracked at $600 \mathrm{hPa}$ [see section 2c(4)]. Figure 9a shows the longitude-pressure cross section of the meridional wind (broadband-filtered to isolate the westwardmoving component) at $12^{\circ} \mathrm{N}$ regressed onto the vorticity centers in all five longitudinal sectors (shown by rectangles in Fig. 2a). The meridional wind is further partitioned by projection onto the horizontal structures of the WMRG, R1, and R2 equatorial waves at each level. As described in section $2 \mathrm{~b}$, the equatorial waves form a relevant choice of orthogonal basis functions. The sum of the projections onto R1 and R2 captures most of the structure associated with the vorticity in the AEW itself. It is a convenient way to separate equatorial Rossby wave motion from other components, even though it is not expected that the R1 and R2 components evolve as the corresponding modes would on a resting background state.
It is seen that all the wave components increase in amplitude toward the west, being stronger over the east Atlantic than over Africa. Over the ocean $\left(30^{\circ} \mathrm{W}\right)$ the tilt of the wave components is weak. The equatorial Rossby wave component is deep, resembling an equivalent barotropic structure. However, the WMRG wave has a clear zero node at about $300 \mathrm{hPa}$ where the structure changes sign. This is consistent with the first baroclinic vertical structure that arises in the calculation of normal modes by separation of variables on a resting basic state.

However, over West Africa, the equatorial Rossby wave component (Fig. 9b) tilts eastward with height (upshear) below the $\mathrm{AEJ}$, at about $600 \mathrm{hPa}$, and westward above it which is a necessary configuration for baroclinic wave growth (Thorncroft and Blackburn 1999; Berry and Thorncroft 2005; Cornforth et al. 2017). Note that in the full $v$ (westward filtered) the tilt below the AEJ is not so apparent, although the westward tilt above the AEJ is clear, which indicates that the projection onto equatorial Rossby wave components does serve to isolate the tilt and connection with the baroclinic growth mechanism (through counterpropagating Rossby waves). 

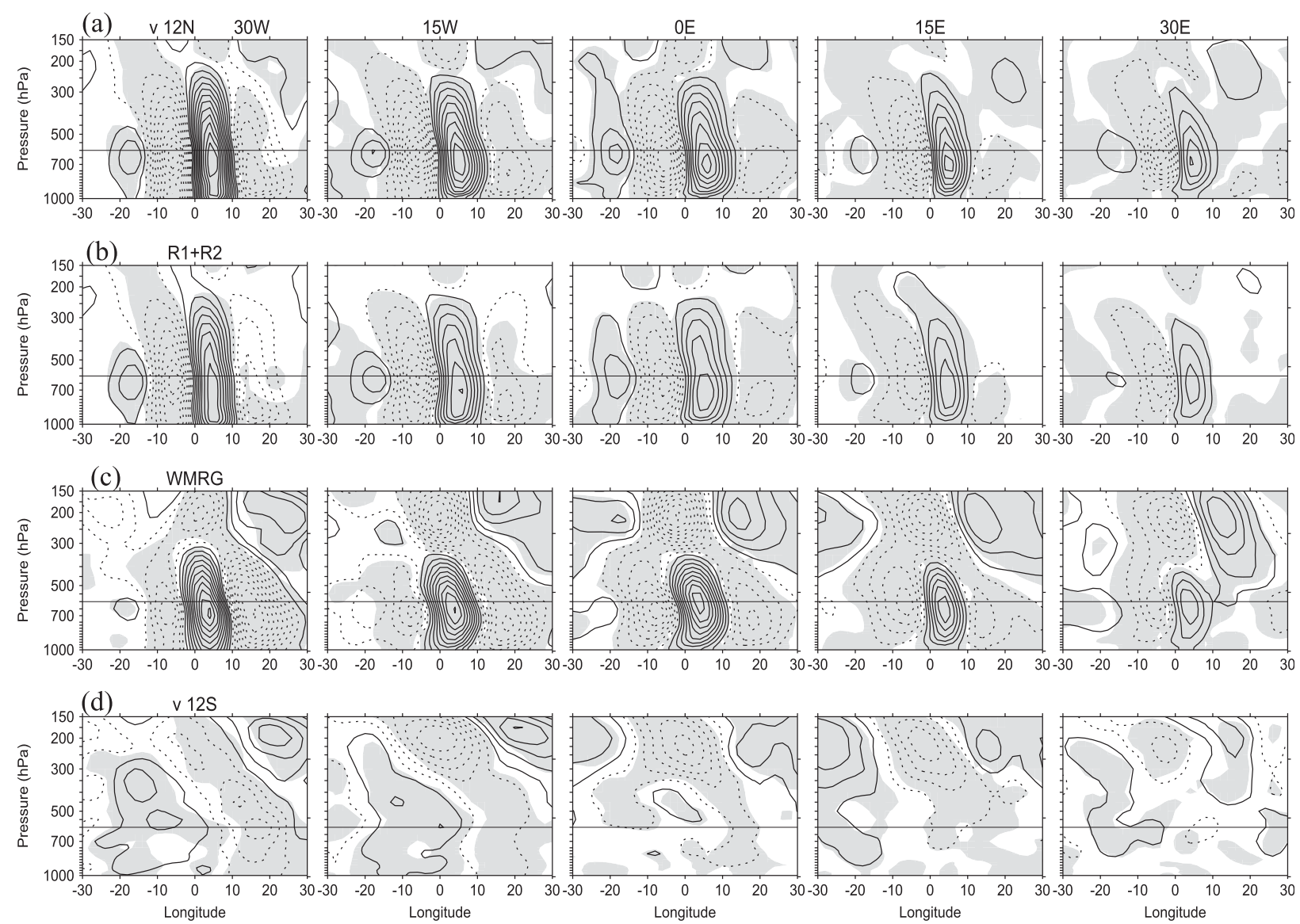

FIG. 9. Longitude-height cross sections for meridional wind regressed onto AEW vorticity centers in five regions, centered at (left to right) $30^{\circ} \mathrm{W}, 15^{\circ} \mathrm{W}, 0^{\circ}, 15^{\circ} \mathrm{E}$, and $30^{\circ} \mathrm{E}$. (a) Westward-filtered $v$ at $12^{\circ} \mathrm{N}$, (b) the equatorial Rossby wave structures $\mathrm{R} 1$ plus $\mathrm{R} 2$ at $12^{\circ} \mathrm{N}$, (c) WMRG waves at $0^{\circ}$, and (d) westward-filtered $v$ at $12^{\circ} \mathrm{S}$. Each panel shows longitude relative to the vorticity centers that pass through the region. The solid (dotted) lines indicate positive (negative) values. In (a) and (b), the contours start at $\pm 0.2 \mathrm{~m} \mathrm{~s}^{-1}$, with an interval of $0.4 \mathrm{~m} \mathrm{~s}^{-1}$. In (c) and (d), the contours are halved. In the shaded areas, regressed values exceed the $95 \%$ significance level.

The WMRG waves (Fig. 9c) also tilt eastward below the AEJ and westward above it. However, the signature of the first baroclinic structure is retained with winds in the upper troposphere having opposite sign to those below, in addition to the westward tilt above the AEJ. However, the zero node varies in altitude from $300 \mathrm{hPa}$ at $30^{\circ} \mathrm{W}$ to $400 \mathrm{hPa}$ at $15^{\circ} \mathrm{E}$. It is interesting that the WMRG wave structures in the upper troposphere (above the zero node) also exhibit slightly longer wavelengths than in the lower troposphere (quantified in the next section). For $v$ at $12^{\circ} \mathrm{S}$ (Fig. 9d), a significant wave signal is found only in the upper troposphere. It is interesting that its pattern is very similar in wavelength and phase to that of the upper-tropospheric WMRG waves, suggesting a connection between the WMRG and SH uppertropospheric RWs (examined in section 6). The lack of coherent signal in the lower troposphere shows that the motions in the $\mathrm{SH}$ at this level are uncorrelated with
AEWs across West Africa. Therefore, the signature seen in the WMRG projection in the lower troposphere is dominated by the $\mathrm{NH}$.

\section{c. Zonal propagation characteristics}

The zonal propagation characteristics of waves identified in the meridional wind are quantified in the $\mathrm{NH}$ (at $12^{\circ} \mathrm{N}$ ), the $\mathrm{SH}\left(\right.$ at $12^{\circ} \mathrm{S}$ ), and for the WMRG structure (at the equator). Three propagation parameters - the zonal wavenumber $(k)$, period $(p)$, and phase speed $(c)$ - are obtained from the regression fields as a function of longitudinal sector and time lag (fields similar to Fig. 11e). The zonal phase speed $c$ is calculated from this regressed field using the Radon transform method (Radon 1917; Yang et al.2007b). The range of $k$ and $p$ characteristic of the variability in each wave component is estimated from longitude-lag diagrams.

Table 1 shows these propagation parameters for the following fields regressed onto the vorticity value at the 
TABLE 1. Climatological mean of zonal wavenumber $(k)$, period $(p)$, and zonal phase speed $(c)$ of meridional wind disturbances obtained by regression onto the positive vorticity centers tracked within AEWs for the longitudinal sector centered on $0^{\circ}$. Results are obtained for westward-filtered $v$ at $12^{\circ} \mathrm{N}$ and $12^{\circ} \mathrm{S}$ and the projection of $v$ on to WMRG waves. Here $k$ and $p$ are estimated from the regressed longitude-lag diagrams (as in Fig. 11e), and $c$ is calculated from the Radon transform method (Radon 1917). Phase speed of vorticity centers is also indicated in parentheses.

\begin{tabular}{lccc}
\hline \hline \multicolumn{1}{c}{ Wave $v$} & $k$ & $p$ (days) & $c\left(\mathrm{~m} \mathrm{~s}^{-1}\right)$ \\
\hline 700-hPa $v$ at $12^{\circ} \mathrm{N}$ & $12-13$ & $3-4$ & $9.1(8.4)$ \\
200-hPa WMRG & $8-9$ & $4-5$ & 11.9 \\
700-hPa WMRG & $11-12$ & $3-4$ & 11.0 \\
200-hPa $v$ at $12^{\circ} \mathrm{S}$ & $7-8$ & $4-5$ & 12.7 \\
\hline
\end{tabular}

tracked AEW centers in the region centered at $0^{\circ}: v$ $\left(12^{\circ} \mathrm{N}, 700 \mathrm{hPa}\right), v\left(12^{\circ} \mathrm{S}, 200 \mathrm{hPa}\right)$, and the WMRG equatorial $v$ at 700 and $200 \mathrm{hPa}$. The westward-filtered $v\left(12^{\circ} \mathrm{N}, 700 \mathrm{hPa}\right)$ is dominated by AEWs and, therefore, has a characteristic phase speed $c\left(9.1 \mathrm{~m} \mathrm{~s}^{-1}\right)$, which is close to the average zonal speed of the tracked vorticity centers $\left(8.4 \mathrm{~m} \mathrm{~s}^{-1}\right)$. The characteristic zonal wavenumber is $12-13$ and the period is $3-4$ days. Interestingly, the period $p$ is quite similar for the AEWs, WMRG component, and the upper-tropospheric wave activity in the SH. The period is found to be slightly longer in the upper troposphere (4-5 days) than lower troposphere (3-4 days). However, since WMRG waves have $k$ of 11-12 in the lower troposphere and $k$ of 8-9 in the upper troposphere, they have quite similar phase speed $c\left(11\right.$ and $\left.11.9 \mathrm{~m} \mathrm{~s}^{-1}\right)$. The difference in zonal wavelength for WMRG waves in the upper and lower troposphere has already been noted from Fig. 9c.

The AEW at $700 \mathrm{hPa}$ has a wavelength longer than early studies on AEWs that only used low-level meridional wind (e.g., Burpee 1974) or relative vorticity for a limited period $(k=14-19)$, but slightly shorter than some later studies $(k=8-13)$; for example, Kiladis et al. (2006), where AEW structures were obtained by statistical regression of winds onto westward-filtered OLR. Our study shows that the WMRG waves over West Africa have a longer wavelength, particularly in the upper troposphere, and move at similar westward phase speed to AEWs (although faster). Therefore, we deduce that the longer wavelength derived statistically in those studies using OLR is representative of the uppertropospheric WMRG wave component, rather than the vorticity wave on the AEJ.

The westward-filtered $v$ at $12^{\circ} \mathrm{S}$, which is a signature of SH RWs in the upper troposphere, has the same period as the WMRG waves (4-5 days) and slightly smaller wavenumber $k(7-8)$ and, therefore, on average slightly faster westward phase speed $c\left(12.7 \mathrm{~m} \mathrm{~s}^{-1}\right)$. The mechanism connecting these $\mathrm{SH}$ upper-tropospheric Rossby waves and WMRG waves is investigated in section $6 \mathrm{~d}$.

\section{Years with strong and weak AEW activity and evidence for a major role of Rossby waves propagating from the Southern Hemisphere}

The strong interannual variability of AEW occurrence has already been discussed in the introduction and Fig. $2 c$ shows the marked variability in average AEW intensity between years. In this section, dynamical mechanisms that might explain the interannual variability are sought. In section $6 \mathrm{a}$, the wave activity throughout the tropics between $75^{\circ} \mathrm{W}$ and $45^{\circ} \mathrm{E}$ is characterized for 6 years with the strongest AEW strength and the six weakest (labeled in Fig. 2c). In section $6 \mathrm{~b}$, mechanisms for amplification of AEW vorticity centers by WMRG waves are explored. In section $6 c$, it is shown that the differences in seasonalmean zonal flow between the years with strongest and weakest AEW activity are much larger in the upper troposphere than lower troposphere, extending the findings of Nicholson (2009) who examined a single strong and weak AEW year. Then in section 6d, Doppler shifting of WMRG waves by basic zonal flows is shown. Finally in sections $6 \mathrm{e}-\mathrm{g}$, the theory for the propagation of RWs and equatorial WMRG waves is used to relate the marked differences in wave activity to the time-mean flow in each season, and a diagnosis of the connection between WMRG waves and $\mathrm{SH}$ RWs is present. Dynamical explanations are explored that link enhanced AEW activity to enhanced activity of WMRG waves and RWs propagating from the $\mathrm{SH}$ into the tropical waveguide.

\section{a. Differences in tropical wave activity between years with strong and weak AEW activity}

Figure 10 shows a longitude-height cross section of the standard deviation of meridional wind $[\operatorname{SD}(v)]$ for westward-filtered disturbances at $12^{\circ} \mathrm{N}, 0^{\circ}$, and $12^{\circ} \mathrm{S}$ and the WMRG wave structures, for the six strongest AEW years (left column), six weakest AEW years (middle column), and the difference between them (right column). As in the climatology (Fig. 4), for both strong and weak AEW years, the $\operatorname{SD}(v)$ at $12^{\circ} \mathrm{N}$ in the lower troposphere shows a local maximum over West Africa and the east Atlantic where AEWs are prevalent. This low-level maximum also appears to a lesser extent for $\operatorname{SD}(v)$ at $0^{\circ}$ and for the WMRG wave. As expected, at $12^{\circ} \mathrm{N}$ and the equator the lowertropospheric activity is significantly stronger for the strong AEW years than in the weak years (significance 



FIG. 10. Longitude-height cross section of standard deviations in meridional wind ( $\mathrm{m} \mathrm{s}^{-1}$ ) averaged for (left) six strong, (middle) six weak AEW years, and (right) the difference between them. Westward-filtered $v$ at (a) $12^{\circ} \mathrm{N}$, (b) $0^{\circ}$, and (c) $12^{\circ} \mathrm{S}$ and (d) WMRG at $0^{\circ}$. In the difference fields, the shaded areas denote values exceeding the $95 \%$ significance level (given variability between years).

level $>95 \%$ from the Student's $t$ test). However, the WMRG waves show that they are also significantly enhanced in the upper troposphere at the longitudes with lower-tropospheric activity. The WMRG component shows two distinct maxima in altitude in strong AEW years indicating that the lower- and uppertropospheric variability maybe distinct (they have already been shown to have distinct wavenumbers).

There is also an upper-tropospheric maximum in $\mathrm{SD}(v)$ in the range $75^{\circ}-10^{\circ} \mathrm{W}$ for westward-filtered disturbances at $12^{\circ} \mathrm{S}$ and on the equator, as well as for WMRG waves, which is significantly stronger in strong AEW years (Figs. 10c and 10d). The reasons for this are explored in section $6 \mathrm{c}$.

\section{b. Mechanisms for amplification of AEW vorticity centers by WMRG waves}

The close connection between increased WMRG wave activity and AEW activity suggests the importance of the WMRG wave for the development of the AEWs and interannual variability. The consistent phase relationship between the AEW vorticity centers and the WMRG wave structure in the lower and upper troposphere has already been shown in Fig. 8 through the regression analysis. Here, Figs. 11a,b show the 200-hPa horizontal winds for westward-filtered disturbances and the WMRG structures, both regressed onto the vorticity centers passing through the region centered at $0^{\circ}$. The results are shown for the entire climatology, strong and weak AEW years. It is clear that in all cases there are strong large-scale circulations extending across the equator, with the crossequatorial motion dominated by the WMRG structure and southward cross-equatorial flow at the longitude of the vorticity center. The winds are in the correct phase to amplify the vorticity centers through vortex stretching. Cross-equatorial flows are weaker for climatology and weak AEW years.

The hypothesized mechanism of vorticity stretching by the WMRG waves is explored in Fig. 11c, which shows the longitude-height cross section of vorticity stretching, $-f^{*} D$ averaged over $5^{\circ}-18^{\circ} \mathrm{N}$ for the winds 

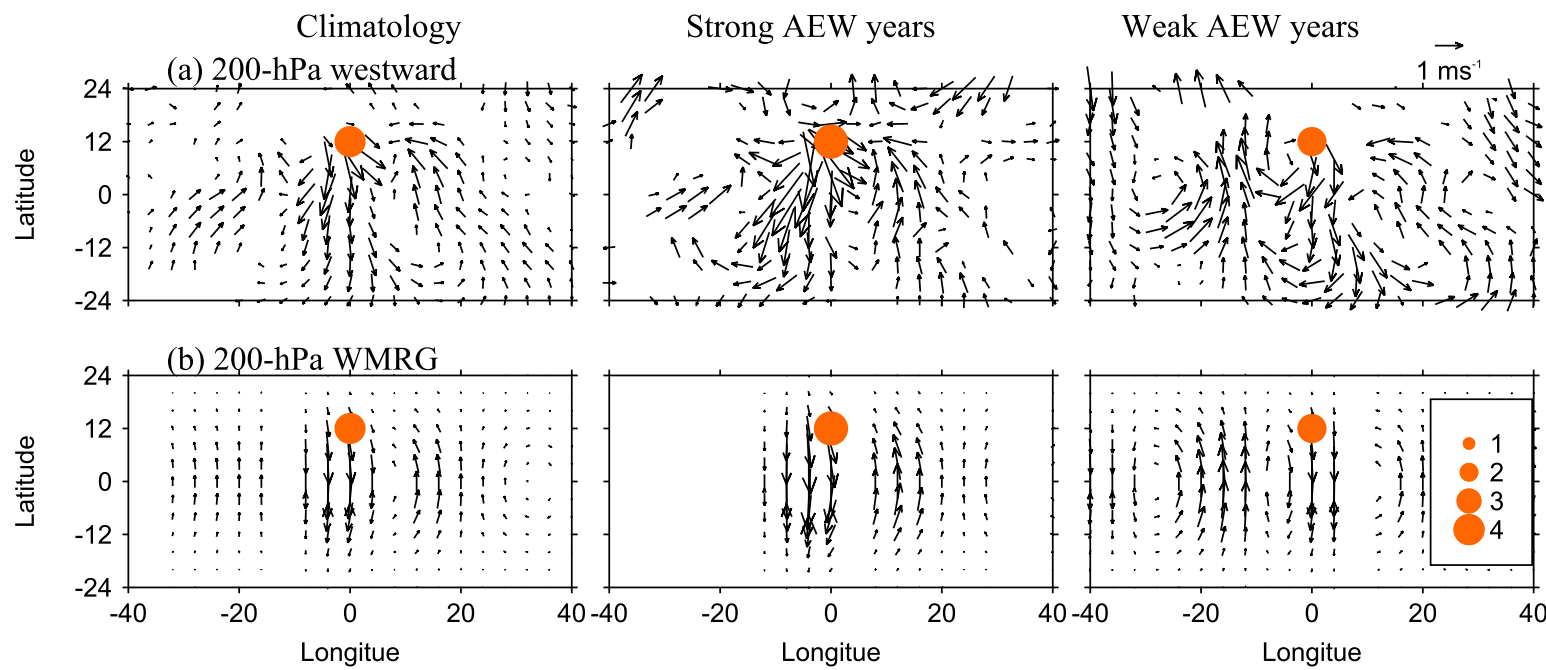

(c) WMRG vorticity stretching $-f^{*} D$
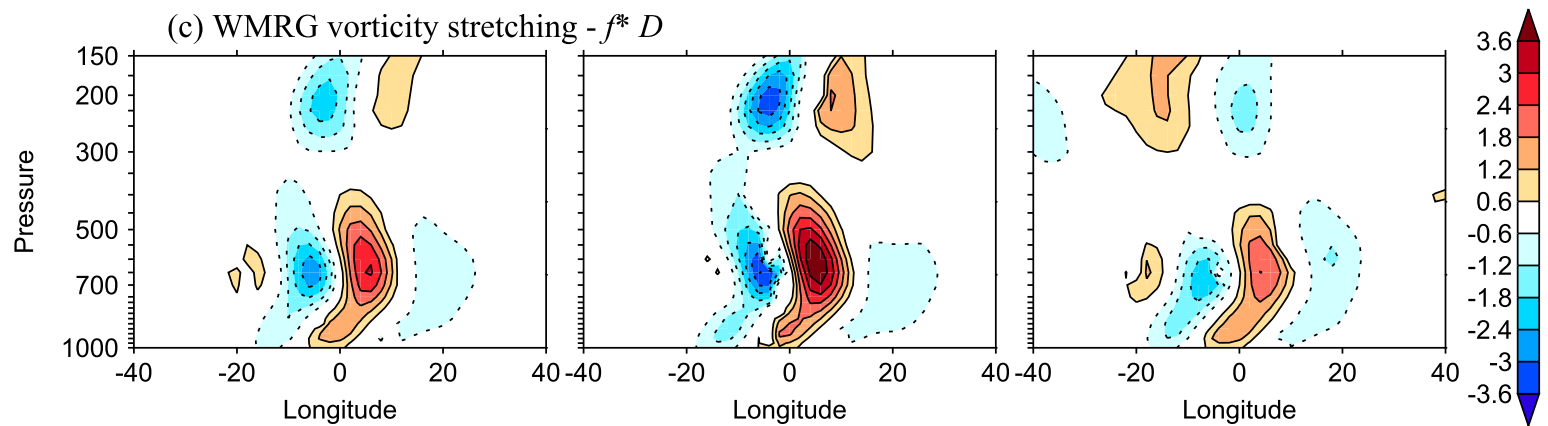

(d) Lag-height diagram of WMRG $v$
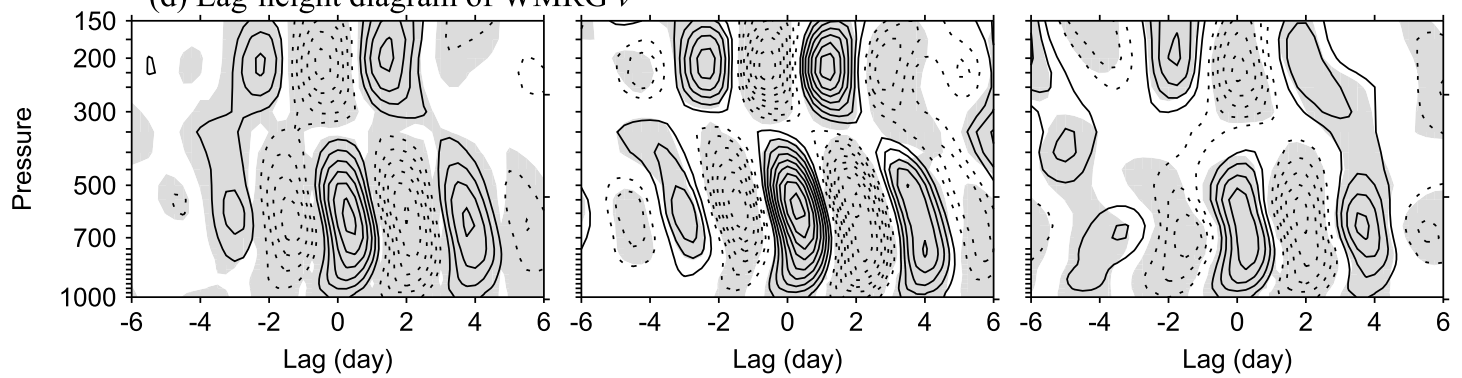

(e) Longitude-lag diagram of 200-hPa WMRG $v$


FIG. 11. Fields regressed onto AEW vorticity centers in the region centered on $0^{\circ}$, averaged for (left) climatology, (middle) six strong, and (right) six weak AEW years. (a) The 200-hPa westward-filtered winds. (b) The 200-hPa WMRG structures. (c) Vorticity stretching by the WMRG component averaged over $5^{\circ}-18^{\circ} \mathrm{N}\left(\times 10^{-11} \mathrm{~s}^{-2}\right)$. (d) Lag-height diagram of WMRG equatorial $v$, with the AEW vorticity center located at day 0 . Solid (dotted) lines indicate positive (negative) values with a contour interval of $0.3 \mathrm{~m} \mathrm{~s}^{-1}$. (e) Longitude-lag 
projected onto WMRG waves. Here $f^{*}$ denotes the basic-state absolute vorticity $(f-d U / d y)$ and $D$ is the horizontal divergence in the WMRG wave. The diagnostic reveals that the term is positive at the location of the AEW vorticity center $\left(0^{\circ}\right.$ on the shifted longitude axis) and to its east, implying that the WMRG structure acts to intensify the vorticity center and to hinder its propagation toward the west. In weak AEW years, the vorticity stretching is weaker, about $60 \%$ of that for strong years at $600 \mathrm{hPa}$. The peak magnitude of vorticity stretching at $600 \mathrm{hPa}$ in strong AEW years is about $4 \times 10^{-11} \mathrm{~s}^{-2}$, which corresponds to a vorticity tendency of $0.13 \times f$ day $^{-1}$, which is strong relative to the observed rate of amplification (e.g., see Fig. 5).

To examine the time evolution of the WMRG wave and its connection to the AEW in the lower troposphere, Fig. 11d shows a lag time-height diagram of the WMRG waves, where the independent variable is the maximum vorticity in the AEW trough and the dependent variable (meridional wind of the WMRG component) is regressed with varying time lags such that "day 0" corresponds to the time of maximum vorticity. This indicates that in strong AEW years the upper-tropospheric WMRG waves are much more prevalent than in the climatology and the weak AEW years, and this is also true in the lower troposphere.

Figure 11e presents the longitude-time diagram for WMRG waves at $200 \mathrm{hPa}$ regressed onto the vorticity of the AEW centers. The WMRG northerly wind is in phase with the vorticity centers at the beginning of the vorticity track in years of strong AEWs, consistent with vortex stretching as a mechanism to intensify the vorticity. However, an important feature is that well before the vorticity track starts, there are WMRG wave trains with eastward group velocity propagating into the region from the Atlantic, especially in strong AEW years. This provides evidence that the WMRG waves indeed play an important role in the amplification of the AEWs, rather than the WMRG waves being an inherent part of the AEW structure. The difference in westward phase speed between the WMRG waves and AEWs is also clear. It is also interesting to note that in strong AEW years at around $0^{\circ}$ longitude the WMRG wave packet has near-zero group velocity, and in negative lag days to the east of $0^{\circ}$ there is also a weak wave train with westward group speed. As will be shown below, this variation in the WMRG group velocity is consistent with the change in the dispersion relation of the WMRG wave caused by the change in the basic zonal winds, and the near-zero group velocity around $0^{\circ}$ longitude suggests the wave energy accumulation there.

The abovementioned analysis shows that there is a strong relationship between developing AEW vorticity centers in the NH lower troposphere and WMRG waves. Figures 8 and 9 show that in the lower troposphere, there is northward cross-equatorial flow and a maximum in convergence just to the east of the vorticity center. In the upper troposphere, there is a maximum in divergence as part of WMRG structures just to the west of the vorticity center, and associated southward flow across the equator. This phase relationship is similar to the one Besson and Lemaitre (2014) identified with intense and long-lived mesoscale convective systems (MCSs) embedded within AEWs close to the positive vorticity center. The MCS occurs where there is ascent precisely between upperlevel divergence to the west and low-level convergence to the east (see their Fig. 5). Besson and Lemaitre (2014) describe the upper-tropospheric feature as a "TEJ streak." Deep convection and latent heat release occurs within the MCS and this would act as a positive feedback onto the ascent associated with the tilted WMRG structure. The ascent shown in their work is in the correct phase to amplify the low-level positive vorticity center by vortex stretching.

The average location of convection relative to vorticity centers is shown in Fig. 12. OLR and westward-filtered horizontal winds in the upper and lower troposphere are regressed onto the AEW vorticity centers in the two longitudinal sectors centered at $15^{\circ} \mathrm{W}$ and $0^{\circ}$ (for strong AEW years). It is seen that intensified convection (negative OLR anomaly) is collocated with the positive vorticity centers and on their eastern flank where the lower-tropospheric cross-equatorial flow from the $\mathrm{SH}$ is strongest, but also where the vortex stretching by the WMRG component is strongest. It illustrates the connection between the AEW vorticity at $700 \mathrm{hPa}$, ascent, OLR (as a proxy for deep convection), upper-level divergence, and cross-equatorial motion as part of a WMRG wave. The latent heat release within convection is in the correct phase to amplify the vertical motion and AEW vorticity. This is consistent with importance of moisture in simulations of AEW variability in Cornforth et al. (2009). The large meridional extent of winds associated with the OLR in the AEWs is

diagram of 200-hPa WMRG equatorial $v$. Red circles are autoregressed vorticity centers $\left(\times 10^{-5} \mathrm{~s}^{-1}\right)$. In (a), (b), (c), and (e) only winds exceeding the significance level of $95 \%$ are shown. In (d), the shaded areas denote regions of regressed values exceeding the $95 \%$ significance level. 



(b) OLR and 700-hPa winds
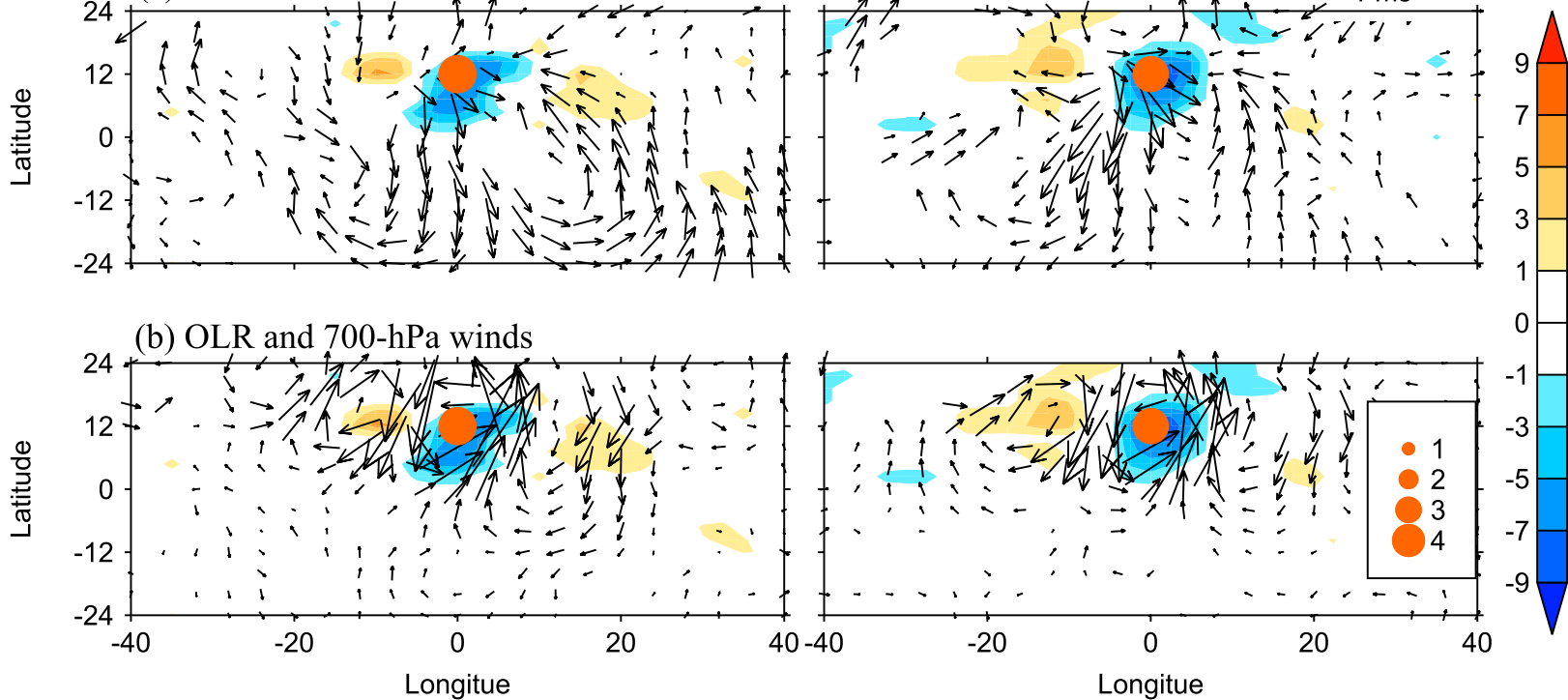

FIG. 12. Westward-filtered OLR (color, $\mathrm{W} \mathrm{m}^{-2}$ ) and horizontal winds at (a) 200 and (b) $700 \mathrm{hPa}$ in strong AEW years, regressed onto vorticity centers in two regions centered at (left) $15^{\circ} \mathrm{W}$ and (right) $0^{\circ}$. Other conventions are as in Fig. 8 . Only winds exceeding the $95 \%$ significance level are shown.

consistent with that shown in Kiladis et al. (2006). They suggest that the convection associated with AEWs is initiated by dynamical forcing, which leads to vertical motion at low levels and couples the AEW to deep convection.

Note that this synoptic-scale explanation for the link between seasons with stronger vorticity centers in AEWs and enhanced WMRG activity differs markedly from the argument made by Nicholson (2009) that enhanced season-averaged precipitation in years of strong AEW activity was a result of greater time-mean ascent in the rain belt and a stronger TEJ. The stronger precipitation must be associated with stronger ascent (through the time-mean thermodynamic budget typical of the tropics) and together they are related to a stronger meridional circulation, southward flow in the upper troposphere, and a stronger TEJ to the south of the rain belt. This is a diagnostic relationship, not a causal one. In the following section, the differences in seasonal-mean zonal flow between years with strong and weak AEWs will be calculated and then in sections $6 \mathrm{~d}$ and $6 \mathrm{e}$ they will be used as input to diagnose the Doppler shifting of WMRG waves and to wave propagation theory to explain why wave activity is greater when the TEJ is strong.

\section{c. Difference in basic zonal flow between years of strong and weak AEW activity}

Figure 13 shows seasonal-mean zonal winds in the upper and lower troposphere, averaged for the six strongest and six weakest AEW years and the difference between them. In the lower troposphere, the difference in the zonal winds is small with the easterly flow being slightly weaker over $0^{\circ}-15^{\circ} \mathrm{N}$ in strong AEW years. Note that on a meandering jet, if the meanders (or waves) have greater amplitude then the zonal average of the flow has a weaker magnitude, even if the wind speed along the curvy jet core is the same. This effect may explain the slight reduction in easterly flow in years of strong AEWs.

The zonal flow difference in the upper troposphere is far greater and dominated by easterly anomalies. The time-averaged zonal wind is anomalously easterly in strong AEW years in the equatorial region and the $\mathrm{SH}$ tropics across the Atlantic and southern Africa. The equatorial easterly flow is stronger and the westerly flow in the $\mathrm{SH}$ (south of $5^{\circ}-10^{\circ} \mathrm{S}$ ) is weaker. This is consistent with the finding of Nicholson (2009). Now the ramifications of seasonal-mean zonal flow differences for the propagation and activity of RWs and equatorial WMRG waves are investigated. Enhanced activity in WMRG waves above West Africa is expected to enhance AEW activity through the vortex-stretching mechanism described in the last section.

\section{d. Doppler shift of WMRG waves by stronger easterlies}

To examine the influence of extratropical RWs on tropical WMRG waves, it is instructive to analyze the 


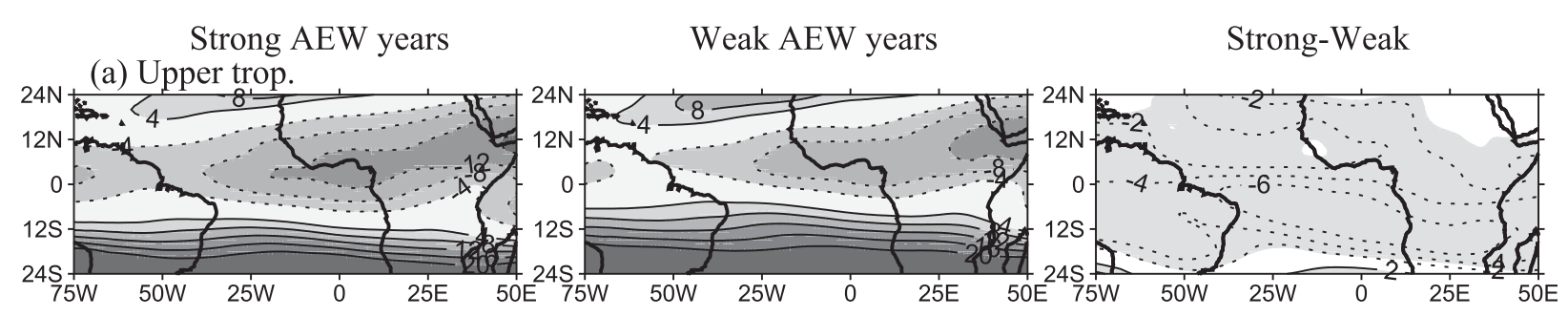

(b) Lower trop.
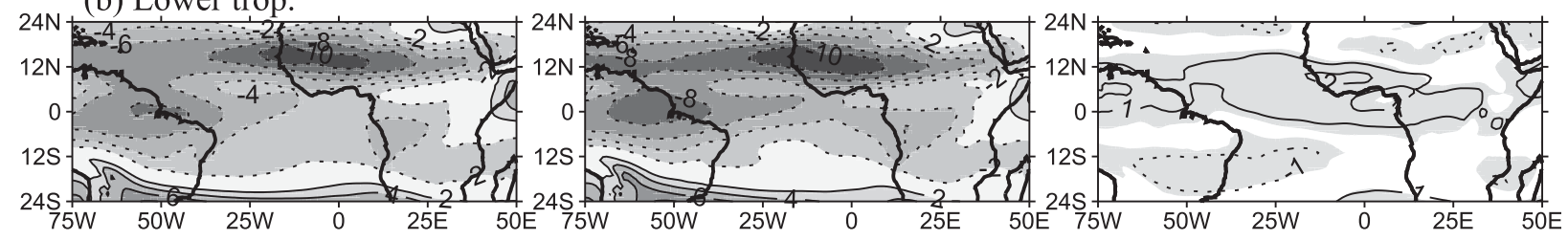

FIG. 13. Zonal winds averaged over (a) the upper troposphere (200-300 hPa) and (b) lower troposphere (600-700 hPa). Composite for (left) six strong AEW years, (middle) six weak AEW years, and (right) difference between them over the African-Atlantic sector. The contour interval is $4 \mathrm{~m} \mathrm{~s}^{-1}$ in (a) and $2 \mathrm{~m} \mathrm{~s}^{-1}$ in (b). The shading area in the difference fields indicates the difference values exceeding the $95 \%$ significance level.

properties of equatorial wave dispersion, RW dispersion on the sphere, and the conditions for the reflection or absorption of Rossby wave rays.

Figure 14a shows the observed time-mean zonal mean flow profile $U(\varphi)$ averaged across the $75^{\circ} \mathrm{W}-45^{\circ} \mathrm{E}$ sector in the upper troposphere for strong (black line) and weak (gray line) AEW years. It is seen that the easterly flow in the tropics is stronger and broader in strong AEW years. The curvature of the broader jet is weaker and, therefore, the effective $\beta$ is closer to the value of planetary vorticity gradient. Figure $14 \mathrm{~b}$ shows two sets of equatorial wave dispersion curves corresponding to two Doppler shifts by $U_{0}$ values (average zonal wind over the longitude sector and latitudes between $+2 y_{0}$ and $-2 y_{0}$ ) in strong and weak AEW years, respectively. The planetary vorticity gradient $\beta_{0}$ is used for the dispersion relations (without considering the relative vorticity of the background flow) to be consistent with the assumptions in the basic equatorial wave theory (Matsuno 1966). Since $U_{0}$ in weak AEW years is small $\left(-1.9 \mathrm{~m} \mathrm{~s}^{-1}\right)$, the corresponding dispersion curves (gray) are not far from the familiar results for a resting atmosphere. In strong AEW years there is stronger easterly flow $\left(-5.8 \mathrm{~m} \mathrm{~s}^{-1}\right)$ and the eastward-moving waves (Kelvin waves and EMRG waves) are Doppler shifted to lower frequency. The westward-moving WMRG and R1 waves are shifted to higher frequency, especially for larger $k$. It is important to note that because of the Doppler shifting, the frequency for WMRG curves becomes very flat across a wide range of $k$. As a result, the period of WMRG waves is almost uniform (3-4 days) in strong AEW years, which is comparable to the period of AEWs. The period range predicted by theory is close to that of the observed WMRG waves (Table 1) and with the typical period of AEWs.

In the easterly environment, the group velocity of WMRG waves $(\partial \omega / \partial k)$ is near zero (solid black curve in Fig. 14b). The eastward group velocity is greater in regions with weaker easterlies for small $k$ (solid gray curve). This implies that the eastward group velocity of WMRG waves must be stronger over South America and the western Atlantic where easterly wind is weaker, while over the African continent the group velocity will become close to zero because of the stronger easterlies. Therefore, wave energy accumulation must occur over West Africa (Hoskins and Yang 2016). This change in the WMRG group velocity is entirely consistent with that shown in Fig. 11e. Ray tracing for WMRG waves with a period of -4 days, following the one-dimensional calculation of Hoskins and Yang (2016), indeed shows that there is energy accumulation over West Africa where the group velocity approaches zero (not shown here). This is consistent with the local maximum in $\mathrm{SD}(v)$ associated with WMRG waves in the upper troposphere over the West African coast (Fig. 10d). Note that Diaz and Aiyyer (2013) applied lag regression analysis to reanalysis data to deduce that AEWs exhibit eastward group velocity to the west of $0^{\circ}$ at all levels over the Atlantic and west coast of North Africa. Although they examined the energetics of wave propagation, they did not make the connection with WMRG waves. The eastward group velocity of the WMRG waves may explain the eastward group velocity observed in their statistical analysis over the west side of West Africa since the two components are difficult to disentangle without the projection step. 



(c) Propagation in strong AEW years
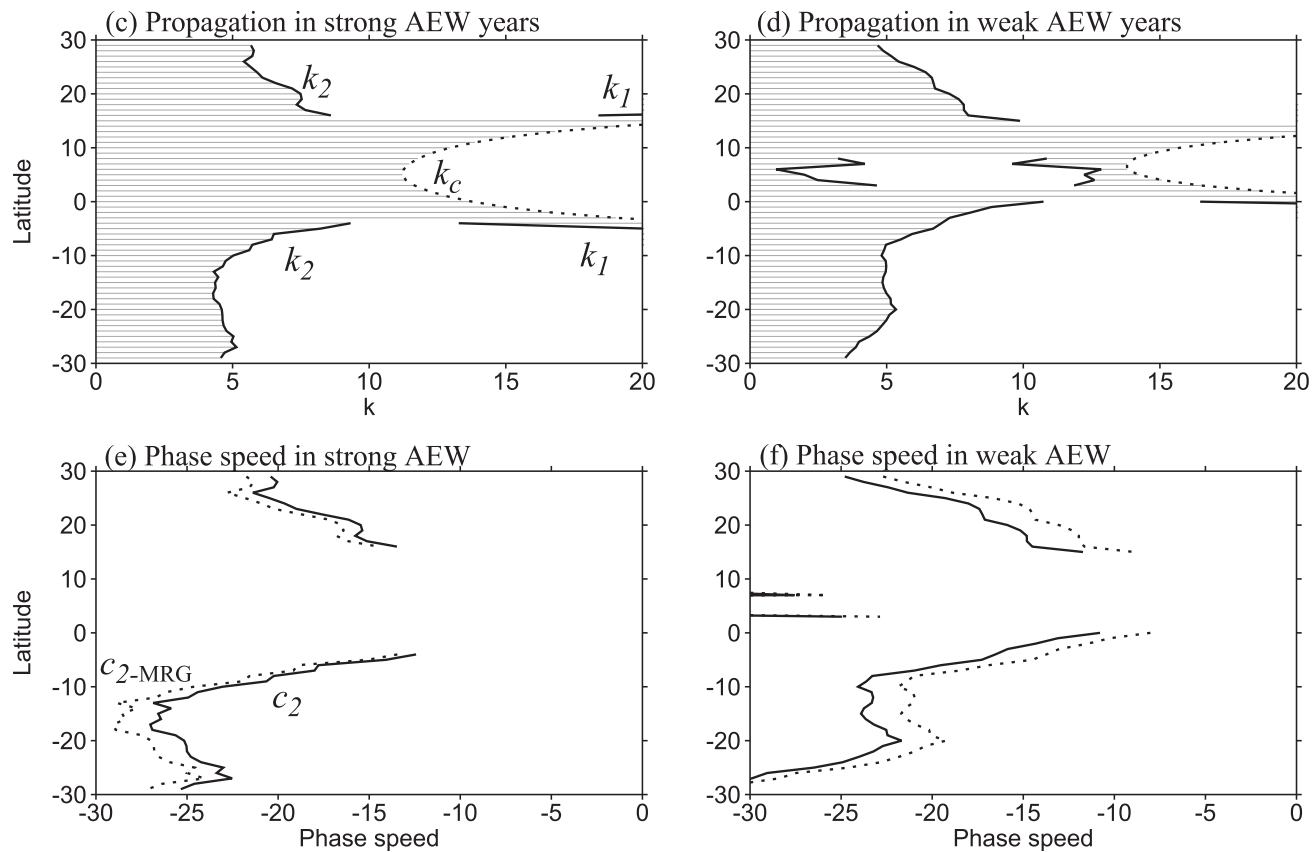

FIG. 14. Basic flow and diagnosis of $\mathrm{WMRG}$ and RW propagation at $200-300 \mathrm{hPa}$ in the sector $75^{\circ} \mathrm{W}-45^{\circ} \mathrm{E}$. (a) $U$ (solid, $\mathrm{m} \mathrm{s}^{-1}$ ) and $\beta$ (dotted, $5 \times 10^{-12} \mathrm{~m}^{-1} \mathrm{~s}^{-1}$ ) for years of strong (black) and weak (gray) AEW activity. (b) Dispersion curves for WMRG (solid), R1 (dashed), and Kelvin (dotted) waves, using $c_{e}=20 \mathrm{~m} \mathrm{~s}^{-1}$, planetary $\beta_{0}=2.28 \times 10^{-11} \mathrm{~m}^{-1} \mathrm{~s}^{-1}$, and $U$ (averaged over $12^{\circ} \mathrm{N}-12^{\circ} \mathrm{S}$ ) in strong (black) and weak (gray) AEW years. (c),(d) Rossby wave propagation diagnosed for period $=-4$ days using observed zonal wind profiles in (c) strong and (d) weak AEW years. Thick solid lines indicate reflection wavenumbers and the dotted line indicates critical wavenumber. Permitted wavenumbers for RW propagation are shaded. (e),(f) Phase speeds ( $\mathrm{m} \mathrm{s}^{-1}$ ) of RW (solid, $c_{2}$ ) along $k_{2}$ line defined in Eq. (7) and WMRG (dotted, $c_{2}$-MRG) calculated from Eq. (9) using the $k_{2}$ with $\beta_{0}$ and $U_{0}$ in (e) strong and (f) weak AEW years.

\section{e. Rossby wave propagation into the tropical waveguide}

Free Rossby wave propagation across the extratropics and in the upper troposphere in the tropics is now analyzed using the barotropic vorticity equation. Following Hoskins and Karoly (1981), Hoskins and Ambrizzi (1993) and others have shown that the Rossby ray paths calculated using this reduced dynamics can explain many prominent equivalent-barotropic stationary wave patterns in the atmosphere. Furthermore, Hoskins and Karoly (1981) have shown that the vorticity equation for disturbances on the sphere viewed from the Mercator projection is formally similar to the equation on a Cartesian $\beta$ plane that simplifies the mathematical analysis. The dispersion relation can be written as follows:

$$
\omega=U_{M} k-\frac{\beta_{M} k}{k^{2}+l^{2}}
$$

where $l$ is the meridional wavenumber, $U_{M}=U / \cos \varphi$, is the zonal angular velocity of the background flow, and $\beta_{M}=2 \Omega \cos ^{2} \varphi / a-d / d y\left[\left(1 / \cos ^{2} \varphi\right) \times d / d y\left(\cos ^{2} \varphi U_{M}\right)\right]$ is the relevant meridional absolute vorticity gradient 
modified by the curvature of the basic zonal wind. In this expression, $a$ denotes Earth's radius, $\varphi$ is latitude, and $y=a \varphi$. From now on, the $M$ subscript will be dropped but it is implicitly understood that the analysis applies to the Mercator projection of a domain spanning the tropics and subtropics. It should be noted that $k$ in all equations is the dimensional zonal wavenumber to be distinguished from that used in the figures where it is the nondimensional value $\tilde{k}=a k$. In the Rossby wave analysis, following previous authors, the convention will be that the zonal wavenumber is positive definite and westward propagation will be associated with $\omega<0$ (in contrast to the convention used for equatorial waves where the wavenumber changes sign).

Hoskins and Karoly (1981) also showed that following RW rays, $\omega$ and $k$ are constants (when $U$ and $\beta$ are independent of $x$ and $t$ ) and $l$ varies such that the dispersion relation [Eq. (7)] is satisfied. Therefore, we can consider $\omega$ as a given parameter and seek conditions on $k$ for the propagation of rays.

As discussed in Hoskins and Ambrizzi (1993), the theory can be successfully applied to a longitudinally varying basic flow, assuming that the variation of $U_{M}$ and $\beta_{M}$ with longitude is on a longer scale than the wavelength of interest. Yang and Hoskins (1996) extended the theory to the propagation of Rossby waves of positive and negative frequency. Following ray paths through a slowly varying medium, the following two behaviors can occur:

(i) The ray approaches a turning latitude when it turns into the zonal direction and $l \rightarrow 0$ and the ray is reflected back toward the equator. When $l=0$, Eq. (7) reduces to the quadratic equation $U k^{2}-$ $\omega k-\beta=0$, which has two roots:

$$
k_{1,2}=\left[\omega \mp\left(\omega^{2}+4 \beta U\right)^{1 / 2}\right] /(2 U) .
$$

(ii) The ray approaches a critical line where $c=\omega / k=U$. As it does so, the meridional scale must shrink, the meridional group velocity decreases and the critical zonal wavenumber $k_{c}=\omega / U$ is only achieved where $l$ asymptotically approaches infinity. Yang and Hoskins (1996) outline the conditions for nonstationary RW propagation with the detailed solution and schematic picture for allowable $k$ in different basic states. It is shown that westward-moving RWs can exist on both westerlies and easterlies. The relevant case here is $\beta>0$ and $\omega<0$ (westward propagation) with different $U$ conditions:

- westerlies $U>0$ : propagation is allowed for any $k<k_{2}$ and there is no critical line.

- weak easterlies $U_{e}<U<0$ : propagation for longer wavelengths $k<k_{2}$ and there is another shorter wavelength band $k_{1}<k<k_{c}$ where propagation is possible. Here the parameter $U_{\mathrm{e}}=-\omega^{2} / 4 \beta$.

- strong easterlies $U<U_{e}$ : propagation is allowed for any $k<k_{c}$ and there are no reflection lines.

Figures $14 \mathrm{c}$, d show the ranges of $k$ where RW propagation is possible at each latitude using the observed zonal wind profiles in strong and weak AEW years, respectively, for a specified period of -4 days (the negative denoting westward phase speed). The period is chosen based on the observed period of AEWs (Table 1). The permitted zonal wavenumber range for propagation (shading) is bounded at high $k$ by critical line absorption (dotted) within the tropics and reflection (solid) curves outside the tropical waveguide. Very different RW propagation features are seen between the strong and weak AEW years.

In strong AEW years, as a result of stronger easterly flow in the $\mathrm{SH}$ and equatorial belt, there is a broad tropical waveguide between the two hemispheres. Rossby wave rays with $6<k<12$ can only propagate westward between $5^{\circ} \mathrm{S}$ and $17^{\circ} \mathrm{N}$ with the 4-day period. Westward longwaves with $k \leq 5$ can exist with a 4 -day period outside the tropical waveguide owing to their stronger westward propagation rate relative to the zonal flow. In contrast for weak AEW years, RWs propagation is not possible between $2^{\circ}$ and $8^{\circ} \mathrm{N}$ with a period of -4 days because $U_{e}<U<0$ across those latitudes. Only waves with very long wavelengths $(k<2)$ are able to propagate through the equatorial region with this period and, therefore, the hemispheres are disconnected for shorter wavelengths.

\section{f. Phase speed matching between Rossby and WMRG waves}

The above analysis shows that stronger easterlies enable RW propagation at zonal wavenumbers and frequencies comparable with AEWs across the tropical belt. However, how does RW activity in the SH subtropics connect with the WMRG wave activity? Consider the influence of the basic state on the WMRG waves. The dispersion relation for the WMRG wave on a uniform flow, $U_{0}$, can be derived from Eq. (3) with meridional mode $n=0$ :

$$
c_{\mathrm{MRG}}=\frac{\omega_{\mathrm{MRG}}}{k}=U_{0}+\frac{c_{e}}{2}\left(1-\sqrt{1+\frac{4 \beta}{k^{2} c_{e}}}\right),
$$

where $U_{0}$ represents an average flow over the equatorial region (between $+2 y_{0}$ and $-2 y_{0}$ ), $\beta_{0}=2 \Omega / a=2.28 \times$ $10^{-11} \mathrm{~m}^{-1} \mathrm{~s}^{-1}$, and $c_{e}=20 \mathrm{~m} \mathrm{~s}^{-1}$ can be deduced from $y_{0}=\left(c_{e} / 2 \beta\right)^{1 / 2}=6^{\circ}$, the best-fit meridional scale to observed wave structures, as mentioned in section $2 \mathrm{~b}$. 
Figures $14 \mathrm{e}, \mathrm{f}$ show the RW phase speed $c_{2}=\omega / k_{2}$ (solid) along the reflection line in Figs. 14c,d and the WMRG phase speed, $c_{2-M R G}$, deduced from Eq. (9) at wavenumber $k_{2}(\varphi)$ (dashed). It is remarkable that the two phase speeds are very close across all latitudes, especially for strong AEW years north of $12^{\circ} \mathrm{S}$. In the short wavelength limit $\beta /\left(k_{2} c_{\mathrm{e}}\right) \ll 1$, the WMRG dispersion relation [Eq. (9)] reduces to the barotropic RW dispersion relation [Eq. (7)] for $l=0$ (at the reflection lines). For longer waves, the matching phase speed is explained by the flatness of the Doppler-shifted WMRG dispersion curve, which has a period close to -4 days for zonal wavenumbers 4-16 (Fig. 14b). The theoretical prediction is consistent with the observed feature that WMRG and disturbances in $v$ at $12^{\circ} \mathrm{S}$ have a similar phase speeds (Table 1 ). Since the phase speeds match, sustained interaction between the Rossby and WMRG waves is expected in the shear flow (in a uniform flow the equatorial wave analysis yields normal modes that cannot interact). For example, in the case study Fig. 7 shows how the winds associated with a Rossby wave in the $\mathrm{SH}$ (centered at about $12^{\circ} \mathrm{S}$ ) are connected with the WMRG wave structure. Figure 10 also shows how SH Rossby wave activity across the Atlantic and South America is much greater during the strong AEW years (Fig. 10c). In contrast, the upper-tropospheric disturbances are not enhanced in the NH (Fig. 10a).

\section{g. Mechanism for excitation of WMRG waves by Rossby waves from the $\mathrm{SH}$}

The connection between WMRG waves and Rossby waves from the $\mathrm{SH}$ is investigated by regressing the full (unfiltered) horizontal winds onto the northerly wind extrema (minimum $v$ ) of the WMRG component. For illustration, the region centered at $15^{\circ} \mathrm{W}$ is chosen (spanning $30^{\circ}$ longitude) because this is where the standard deviation of WMRG waves is greatest (Fig. 4d). Only the seasonal mean and zonal $\left(70^{\circ} \mathrm{W}-50^{\circ} \mathrm{E}\right)$ mean are removed from the winds used in the regression so that no assumptions are made regarding the spatial structure or frequency of the field. Figures 15a,b show the regression fields at lag day -1 for strong and weak AEW years, with negative lag indicating full winds lead the WMRG amplitude in cross-equatorial flow (at shifted longitude $0^{\circ}$ ). It is interesting to see that in strong AEW years, to the southwest of WMRG waves there is a SH extratropical wave train with a zonal wavenumber about 5 and a NW-SE tilt, and the eastern part of the wave train is dominated by WMRG wave structures. Such a wave train arching from the $\mathrm{SH}$ toward the equatorial region is very similar to that in an earlier observational study (Yang and Hoskins 2016), which reveals that WMRG waves in the upper tropospheric eastern Pacific in winter are forced by $\mathrm{SH}$ wave trains arching into the equatorial region. In contrast, this feature is not seen in weak AEW years.

The NW-SE tilt of the eddy structure implies two points about the relation between WMRG waves and Rossby waves:

(i) The pattern is consistent with excitation of the WMRG wave by meridional advection of planetary vorticity by the flow associated with SH Rossby waves. For example, consider a thought experiment where there is no WMRG activity and a Rossby wave is focused on the northern flank of the subtropical jet in the SH. Northward flow to the west of the negative vorticity center in the wave advects more negative vorticity from the south so that there is an anomalously negative vorticity at that location extending to the equator. A similar argument applies to positive vorticity advection to the east. The net result, as depicted by the schematic (see Fig. 19) in Hoskins et al. (1985) is that a vorticity wave amplifies near the equator with a westward shift of $90^{\circ}$ relative to the original wave. Furthermore, although the WMRG wave can be excited by the Rossby wave by this mechanism, the phase is such that the meridional advection by the WMRG wave acts to decrease the amplitude of the Rossby wave to the south. The interaction, therefore, has a directional inference. It also implies that the WMRG waves should have a similar wavenumber to the Rossby waves that excite them and if they can propagate with matching phase speeds then the interaction could be sustained.

(ii) The tilt implies that the momentum flux $\left[u^{*} v^{*}\right]$ is negative, which implies that the meridional component of the Rossby wave flux is northward $\left(F_{y}=-\left[u^{*} v^{*}\right]\right)$.

The momentum flux of the regressed winds is averaged over two wavelength ranges of $144^{\circ}\left(68^{\circ} \mathrm{W}-80^{\circ} \mathrm{E}\right)$ and shown in Fig. 15c, for strong (solid) and weak (dotted) AEW years. In strong AEW years, there is a strong negative $\left[u^{*} v^{*}\right]$ in the $\mathrm{SH}$ peaking at about $20^{\circ} \mathrm{S}$ on the equatorward flank of the subtropical westerly jet where there is the strongest meridional shear. This feature is far weaker in years of weak AEW activity, consistent with the untilted wind structure seen in regression (Fig. 15b). However, the positive momentum flux on the equator is quite similar in the two cases. Therefore, there is a much stronger convergence of Rossby wave activity from the $\mathrm{SH}$ into the tropical waveguide in the strong AEW years.

In addition to the excitation of WMRG waves with similar phase speeds to the SH Rossby waves, the 

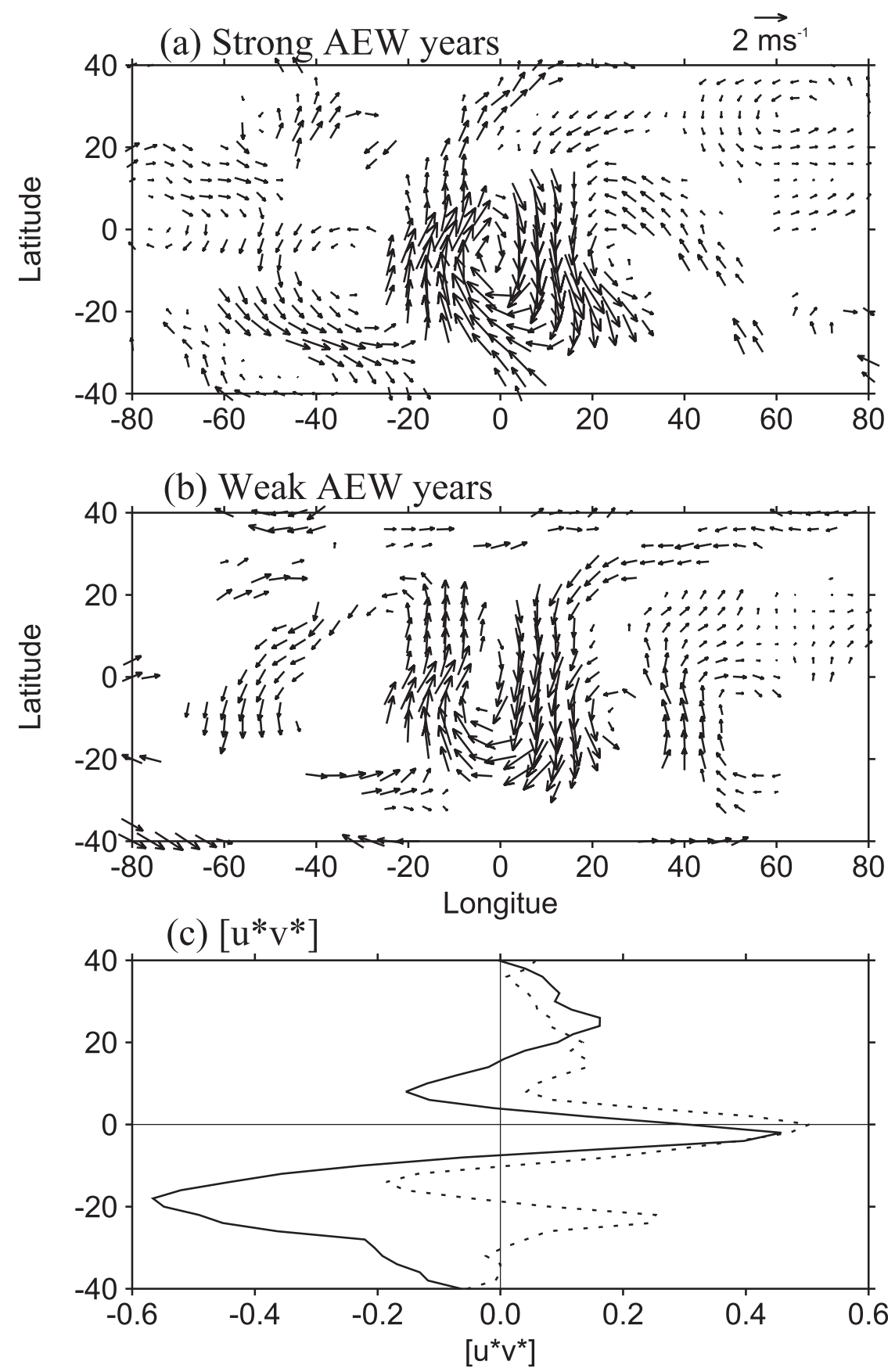

FIG. 15. Horizontal winds (with only the time mean and zonal mean removed) regressed onto 200-hPa WMRG minimum in $v$ (northerlies) in the region centered on $15^{\circ} \mathrm{W}$ spanning $30^{\circ}$ longitude at lag day -1 . (a) Six strong and (b) six weak AEW years. (c) Horizontal momentum flux $\left[u^{*} v^{*}\right]$ of full winds, averaged over $-64^{\circ}$ to $80^{\circ}$ (two wavelengths) for strong (solid) and weak (dotted) AEW years $\left(\mathrm{m}^{2} \mathrm{~s}^{-2}\right)$. Only values exceeding the $95 \%$ significance level are shown in (a) and (b).

momentum flux convergence will accelerate the tropical easterlies in the upper troposphere [i.e., $\left.\partial[u] / \partial t \sim-\left[u^{*} v^{*}\right]_{y}<0\right]$. However, the magnitude is approximately $5 \times 10^{-7} \mathrm{~m} \mathrm{~s}^{-2}$, which is equivalent to
$1.5 \mathrm{~m} \mathrm{~s}^{-1}$ if sustained over 30 days. Therefore, although the Rossby wave convergence into the tropical waveguide gives a positive feedback on the easterly zonal flow (which strengthens the waveguide), the feedback is weak. 


\section{Conclusions}

Dynamical mechanisms influencing the marked interannual variability in African easterly waves were explored by comparing years with the strongest and weakest AEW activity. The biggest differences in the seasonal-mean zonal winds between years of strong and weak AEW activity were found in the upper (rather than lower) troposphere. The tropical easterly jet is stronger in seasons when AEWs are more active, as found by Nicholson (2009). Surprisingly, although the AEWs are examined in the NH lower troposphere, the correlated signal in background wind is strongest in the equatorial and $\mathrm{SH}$ upper troposphere. It is also shown that there is enhanced upper-tropospheric Rossby wave activity in the $\mathrm{SH}$ and equatorial westwardmoving mixed Rossby-gravity wave activity in years with the strongest AEWs.

The dynamical connection between AEWs, WMRG waves, and extratropical equivalent barotropic Rossby waves (RWs) from the $\mathrm{SH}$ has been investigated using ERA-Interim data for the period 1979-2010. The methodology of Yang et al. (2003), based on the projection of broadband-filtered data onto the horizontal structures from equatorial wave theory, is used to identify the equatorial wave components, quantify their variance, and identify relationships between them in the development of AEWs. The analysis is conducted on each pressure level independently, which enables a characterization of the vertical structure and tilt associated with the wave types. AEW propagation was identified by tracking the positive vorticity centers at the level of the African easterly jet $(600 \mathrm{hPa})$.

A case study of the 1995 season was instructive and showed the propagation of the different wave types and the phase relationships between them at times when positive vorticity centers within AEWs intensify. Many of these vorticity centers developed into tropical storms over the Atlantic, some becoming hurricanes. The results were generalized to the entire climatology by using a method whereby all fields were analyzed at longitudes relative to AEW vorticity centers and linear regression was used to extract the structures associated with the vorticity at the tracked center. The results from the case study period were found to be robust and reflect behavior throughout the reanalysis.

Based on the above observations, mechanisms are deduced for the influence of the seasonal-mean zonal flow on RW propagation into the tropics, the excitation of WMRG waves and their role in the transient intensification of AEWs:

- Stronger easterlies enable a broad tropical waveguide for RWs with the characteristic AEW period of -4 days. The RW dispersion analysis shows that the wavenumber range $5<k<12$ is trapped within the tropical waveguide, while longer waves have strong enough westward propagation to attain the period of -4 days outside the easterly waveguide. For $k=5$, waves are observed to propagate from the $\mathrm{SH}$ and converge into the equatorial region (Fig. 15). When easterlies are weaker, Rossby wave propagation is not permitted north of the equator with the period of -4 days, closing the connection between hemispheres.

- Stronger easterlies Doppler shift WMRG waves so that they have a period of about 4 days for a wide range of wavenumbers. In this situation, the tropical waveguide supports Rossby waves with phase speeds that can match Doppler-shifted WMRG waves across the wavenumber range $5<k<12$. This enables sustained interaction of the two waves in the shear flow and excitation of WMRG wave activity through meridional advection of planetary vorticity by $\mathrm{SH}$ Rossby wave disturbances as they propagate westward in step. The dominant wavenumber for WMRG and SH RWs (Table 1) is found to be 7-9 in the upper troposphere with an average phase speed of approximately $12-13 \mathrm{~m} \mathrm{~s}^{-1}$. Therefore, the wave structures that regress onto the AEW vorticity centers (Figs. 8, 9, and 11) have slightly shorter wavelengths than the dominant wavenumber flux from the SH subtropics (Fig. 15).

- Over South America and the tropical western Atlantic, where upper-tropospheric easterlies are weak, the WMRG wave trains have an eastward group velocity and, therefore, packets move eastward. However, over Africa where the easterlies are stronger, the effect of Doppler shifting the WMRG dispersion relation results in near-zero group velocity and, therefore, WMRG wave energy must accumulate above West Africa.

- Individual vorticity centers in AEWs amplify when the phase of the WMRG waves are in a particular configuration. The peak amplitude in AEW vorticity occurs when the maximum low-level convergence in the WMRG wave (and associated northward flow across the equator) is just to the east of the center and the maximum upper-level divergence (and associated southward flow across the equator) is just to the west of the vorticity center. Thus, the westward tilt of the WMRG component is central to vorticity amplification. In the modal WMRG solution on a resting basic state, the upper-level divergence would be associated with upward motion between lower- and upper-tropospheric layers and compensating horizontal convergence below (both layers with matching horizontal structure as in Fig. 1). This mechanism 
can explain the existence of the strong WMRG activity in the lower troposphere over the east Atlantic and West Africa with a vertical structure similar to a tilted first baroclinic mode. However, in shear flow, the wave disturbances are not orthogonal and the vortex stretching associated with the WMRG motion is shown to be in the correct position to amplify the AEW vorticity center. This occurs even though the WMRG waves (in the upper troposphere) are longer and have faster westward phase speeds. The mismatch in phase speed (see Table 1), but approximate match in frequency, implies a periodic amplification of AEWs associated with WMRG waves at the average time scale of 4 days.

- The lower-tropospheric WMRG wave structures advect moisture from the equatorial ocean into West Africa and the OLR signature of deep convection is observed to occur in concert with the AEW vorticity center and on its eastern flank, precisely where the vortex stretching is found to occur. Latent heat release would act as a positive feedback on the ascent within the wave structure and the amplification of vorticity.

- Finally, the RW activity flux from the SH converges in the tropical waveguide in years of strong AEW activity. This acts as a positive feedback since the flux convergence accelerates the easterly flow, broadening the waveguide and enabling the wave interactions described above. However, this effect was found to be a weak feedback but would contribute to maintenance of stronger easterlies.

It is a surprising finding that the interannual variability in AEW activity is more strongly influenced by the background state in the upper troposphere of the $\mathrm{SH}$ than NH. The mechanism proposed here is based on the evidence found in terms of the activity in distinct westward-propagating wave types identified in reanalyses. Fundamental support for the mechanism is based on the dispersion relations for RWs and WMRG waves and their propagation relative to a smoothly varying background flow (assumed to be represented by the seasonal mean). Therefore, the links are nonlocal and connect the hemispheres. They are mediated by waves with nonzero frequency, as opposed to the more typical teleconnections identified with stationary Rossby waves. An important consequence is that interannual variability of precipitation across West Africa, and longer-term climate change, is unlikely to be explained solely by local mechanisms, such as the influence of the land surface.

This study has focused on the influence of background zonal flow on wave propagation characteristics. However, it does not preclude two-way interaction where the
TEJ is stronger as a result of greater AEW activity. Also, it does not dismiss other processes that are important for the initiation and intensification of AEWs. Greater AEW activity is associated with more deep convection, latent heat release, and time-mean ascent in the rain belt across West Africa. Nicholson (2009) notes this occurs in a year with strong AEW activity and also that the equatorward flow from upper-level divergence is stronger and so is the TEJ, as would be expected from an enhanced meridional circulation and Coriolis-effect turning the southward flow. A positive feedback between enhanced upper-tropospheric equatorial easterlies and AEW activity is plausible. However, there are many other remote influences on the TEJ-for example, the outflow from the Asian summer monsoon convection and the wave-activity flux convergence from $\mathrm{SH}$ Rossby waves. Therefore, the mechanisms proposed here cannot compose a closed explanation of AEW interannual variability, and it would be interesting to explore in more detail the origins of variability in uppertropospheric zonal flow across the tropical Atlantic, especially in the SH.

The wave theory used in this study is also far from a complete description of wave behavior in the atmosphere. The equatorial wave theory defining the horizontal structures used for projection of the data does not take into account shear in the zonal flow. This is a limitation, particularly across West Africa where the strong shears associated with the AEJ are essential to the existence of AEWs. However, the analysis suggests that the observed wave structures do bear some relation to the horizontal structure of the WMRG mode and that vertical shear lends the waves a slight tilt, but does not alter them substantially. This suggests that a more complete theory might be possible where the effects of shear are treated as a perturbation to the structures on uniform flows. Several approaches to this problem have been attempted (Andrews and McIntyre 1976; Han and Khouider 2010). Key quantities to predict would be the degree of wave tilt, the structure of vertical motion and its phase relative to the horizontal flow, and the role of latent heat release. It has been argued here that the ascent is central to AEW intensification by WMRG packets entering Africa from the Atlantic.

Acknowledgments. GYY acknowledges the long-term support of the National Centre for Atmospheric Science (NCAS). The research was conducted as part of the NERC Project (NE/I012419/1). We thank the three reviewers for their very helpful comments that encouraged us to improve the analysis and present evidence for wave interaction mechanisms. 


\section{REFERENCES}

Agustí-Panareda, A., and Coauthors, 2010: The ECMWF re-analysis for the AMMA observational campaign. Quart. J. Roy. Meteor. Soc., 136, 1457-1472, https://doi.org/10.1002/qj.662.

Andrews, D. G., and M. E. McIntyre, 1976: Planetary waves in horizontal and vertical shear: Asymptotic theory for equatorial waves in weak shear. J. Atmos. Sci., 33, 2049-2053, https://doi.org/ 10.1175/1520-0469(1976)033<2049:PWIHAV>2.0.CO;2.

Avila, L. A., and R. J. Pasch, 1992: Atlantic tropical systems of 1991. Mon. Wea. Rev., 120, 2688-2696, https://doi.org/10.1175/ 1520-0493(1992)120<2688:ATSO > 2.0.CO;2.

—, and — 1995: Atlantic tropical systems of 1993. Mon. Wea. Rev., 123, 887-896, https://doi.org/10.1175/1520-0493(1995)123<0887: ATSO $>2.0 . C O ; 2$.

Berry, G. J., and C. Thorncroft, 2005: Case study of an intense African easterly wave. Mon. Wea. Rev., 133, 752-766, https:// doi.org/10.1175/MWR2884.1.

,-- , and T. Hewson, 2007: African easterly waves during 2004-Analysis using objective techniques. Mon. Wea. Rev., 135, 1251-1267, https://doi.org/10.1175/MWR3343.1.

Besson, L., and Y. Lemaitre, 2014: Mesoscale convective systems in relation to African and tropical easterly jets. Mon. Wea. Rev., 142, 3224-3242, https://doi.org/10.1175/MWR-D-13-00247.1.

Burpee, R. W., 1972: The origin and structure of easterly waves in the lower troposphere of North Africa. J. Atmos. Sci., 29, 77-90, https://doi.org/10.1175/1520-0469(1972)029<0077: TOASOE $>2.0 . \mathrm{CO} ; 2$.

, 1974: Characteristics of North African easterly waves during the summers of 1968 and 1969. J. Atmos. Sci., 31, 1556-1570, https:// doi.org/10.1175/1520-0469(1974)031<1556:CONAEW>2.0.CO;2.

__ 1975: Some features of synoptic-scale waves based on a compositing analysis of GATE data. Mon. Wea. Rev., 103, 921-925, https://doi.org/10.1175/1520-0493(1975)103<0921: SFOSWB $>2.0 . \mathrm{CO} ; 2$.

Carlson, T. N., 1969a: Synoptic histories of three African disturbances that developed into Atlantic hurricanes. Mon. Wea. Rev., 97, 256-276, https://doi.org/10.1175/1520-0493(1969)097<0256: SHOTAD $>2.3 . \mathrm{CO} ; 2$.

_ 1969b: Some remarks on African disturbances and their progress over the tropical Atlantic. Mon. Wea. Rev., 97, 716-726, https://doi.org/10.1175/1520-0493(1969)097<0716: SROADA $>2.3 . \mathrm{CO} ; 2$.

Cornforth, R. J., B. J. Hoskins, and C. D. Thorncroft, 2009: The impact of moist processes on the African easterly jet-African easterly wave system. Quart. J. Roy. Meteor. Soc., 135, 894 913, https://doi.org/10.1002/qj.414.

— Tropical West Africa: The Forecasters' Handbook, D. J. Parker and M. Diop-Kane, Eds., Wiley, 40-89.

Crétat, J., E. K. Vizy, and K. H. Cook, 2015: The relationship between African easterly waves and daily rainfall over West Africa: Observations and regional climate simulations. $\mathrm{Cli}$ mate Dyn., 44, 385, https://doi.org/10.1007/s00382-014-2120-x.

Dee, D. P., and Coauthors, 2011: The ERA-Interim reanalysis: Configuration and performance of the data assimilation system. Quart. J. Roy. Meteor. Soc., 137, 553-597, https://doi.org/ 10.1002/qj.828.

Diaz, M. L., and A. Aiyyer, 2013: Energy dispersion in African easterly waves. J. Atmos. Sci., 70, 130-145, https://doi.org/ 10.1175/JAS-D-12-019.1.

Diedhiou, A., S. Janicot, S. Viltard, and H. Laurent, 1999: Easterly wave regimes and associated convection over West Africa and the tropical Atlantic: Results from NCEP/NCAR and ECMWF reanalyses. Climate Dyn., 15, 795-822, https:// doi.org/10.1007/s003820050316.

Duvel, J. P., 1990: Convection over tropical Africa and the Atlantic Ocean during northern summer. Part II: Modulation by easterly waves. Mon. Wea. Rev., 118, 1855-1868, https://doi.org/ 10.1175/1520-0493(1990)118<1855:COTAAT $>2.0 . C O ; 2$.

Fink, A. H., and A. Reiner, 2003: Spatiotemporal variability of the relation between African easterly waves and West African squall lines in 1998 and 1999. J. Geophys. Res., 108, 4332, https://doi.org/10.1029/2002JD002816.

Frank, N. L., 1970: Atlantic tropical systems of 1969. Mon. Wea. Rev., 98, 307-314, https://doi.org/10.1175/1520-0493(1970)098<0307: ATSO $>2.3 . \mathrm{CO} ; 2$.

Gill, A. E., 1980: Some simple solutions for heat induced tropical circulations. Quart. J. Roy. Meteor. Soc., 106, 447-462, https:// doi.org/10.1002/qj.49710644905.

- - 1982: Atmosphere-Ocean Dynamics. Academic Press, $662 \mathrm{pp}$.

Hall, N. M. J., G. N. Kiladis, and C. D. Thorncroft, 2006: Threedimensional structure and dynamics of African easterly waves. Part II: Dynamical modes. J. Atmos. Sci., 63, 2231-2245, https://doi.org/10.1175/JAS3742.1.

Han, Y., and B. Khouider, 2010: Convectively coupled waves in a sheared environment. J. Atmos. Sci., 67, 2913-2942, https:/ doi.org/10.1175/2010JAS3335.1.

Hayashi, Y., 1982: Space-time spectral analysis and its applications to atmospheric waves. J. Meteor. Soc. Japan, 60, 156-171, https://doi.org/10.2151/jmsj1965.60.1_156.

Hopsch, S. B., C. D. Thorncroft, K. I. Hodges, and A. Aiyyer, 2007: West African storm tracks and their relationship to Atlantic tropical cyclones. J. Climate, 20, 2468-2483, https://doi.org/ 10.1175/JCLI4139.1.

Hoskins, B. J., and D. J. Karoly, 1981: The steady linear response of a spherical atmosphere to thermal and orographic forcing. J. Atmos. Sci., 38, 1179-1196, https://doi.org/10.1175/1520-0469 (1981)038<1179:TSLROA > 2.0.CO;2.

— alistic longitudinally varying flow. J. Atmos. Sci., 50, 1661-1671, https://doi.org/10.1175/1520-0469(1993)050<1661: RWPOAR $>2.0 . \mathrm{CO} ; 2$.

_ M. E. McIntyre, and A. W. Robertson, 1985: On the use and significance of isentropic potential vorticity maps. Quart. J. Roy. Meteor. Soc., 111, 877-946, https://doi.org/10.1002/qj.49711147002. , and G.-Y. Yang, 2016: The longitudinal variation of equatorial waves due to propagation on a zonal varying flow. J. Atmos. Sci., 73, 605-620, https://doi.org/10.1175/JAS-D-15-0167.1.

Kiladis, G. N., C. D. Thorncroft, and N. M. J. Hall, 2006: Three dimensional structure and dynamics of African easterly waves. Part I: Observations. J. Atmos. Sci., 63, 2212-2230, https:// doi.org/10.1175/JAS3741.1.

Landsea, C. W., 1993: A climatology of intense (or major) Atlantic hurricanes. Mon. Wea. Rev., 121, 1703-1713, https://doi.org/ 10.1175/1520-0493(1993)121<1703:ACOIMA > 2.0.CO;2.

_ , G. D. Bell, W. M. Gray, and S. B. Goldenberg, 1998: The extremely active 1995 Atlantic hurricane season: Environmental conditions and verification of seasonal forecasts. Mon. Wea. Rev., 126, 1174-1193, https://doi.org/10.1175/1520-0493 (1998) 126<1174:TEAAHS > 2.0.CO;2.

Laurent, H., N. d'Amato, and T. Lebel, 1998: How important is the contribution of the mesoscale convective complexes to the Sahelian rainfall? Phys. Chem. Earth, 23, 629-633, https:// doi.org/10.1016/S0079-1946(98)00099-8. 
Liebmann, B., and C. A. Smith, 1996: Description of a complete (interpolated) outgoing longwave radiation dataset. Bull. Amer. Meteor. Soc., 77, 1275-1277.

Mathon, V., H. Laurent, and T. Lebel, 2002: Mesoscale convective system rainfall in the Sahel. J. Appl. Meteor., 41, 1081-1092, https://doi.org/10.1175/1520-0450(2002)041<1081: MCSRIT>2.0.CO;2.

Matsuno, T., 1966: Quasi-geostrophic motions in the equatorial area. J. Meteor. Soc. Japan, 44, 25-43, https://doi.org/10.2151/ jmsj1965.44.1_25.

Mekonnen, A., C. D. Thorncroft, and A. R. Aiyyer, 2006: Analysis of convection and its association with African easterly waves. J. Climate, 19, 5405-5421, https://doi.org/10.1175/JCLI3920.1.

Nicholson, S. E., 2009: On the factors modulating the intensity of the tropical rainbelt over West Africa. Int. J. Climatol., 29, 673-689, https://doi.org/10.1002/joc.1702.

Price, C., Y. Yair, and M. Asfur, 2007: East African lightning as a precursor of Atlantic hurricane activity. Geophys. Res. Lett., 34, L09805, https://doi.org/10.1029/2006GL028884.

Radon, J., 1917: Über die Bestimmung von Funktionen durch ihre Integralwerte längs gewisser Mannigfaltigkeiten. Math.-Phys. Kl., 69, 262-267. [For English translation see Deans, S. R., 1983: The Radon Transform and Some of Its Applications. John Wiley and Sons, 204-217.]

Reed, R. J., D. C. Norquist, and E. E. Recker, 1977: The structure and properties of African wave disturbances as observed during Phase III of GATE. Mon. Wea. Rev., 105, 317-333, https:// doi.org/10.1175/1520-0493(1977)105<0317:TSAPOA > 2.0.CO;2.

Sakai, S., 1989: Rossby-Kelvin instability: A new type of ageostrophic instability caused by a resonance between Rossby waves and gravity waves. J. Fluid Mech., 202, 149-176, https:// doi.org/10.1017/S0022112089001138.

Schreck, C. J., J. Molinari, and A. Aiyyer, 2012: A global view of equatorial waves and tropical cyclogenesis. Mon. Wea. Rev., 140, 774-788, https://doi.org/10.1175/MWR-D-11-00110.1.

Serra, Y. L., G. N. Kiladis, and K. I. Hodges, 2010: Tracking and mean structure of easterly waves over the Intra-Americas Sea. J. Climate, 23, 4823-4840, https://doi.org/10.1175/ 2010JCLI3223.1.

Takayabu, Y. N., 1994: Large-scale cloud disturbances associated with equatorial waves. Part I: Spectral features of the cloud disturbances. J. Meteor. Soc. Japan, 72, 433-449, https://doi. org/10.2151/jmsj1965.72.3_433.

Thorncroft, C. D., and M. Blackburn, 1999: Maintenance of the African easterly jet. Quart. J. Roy. Meteor. Soc., 125, 763-786, https://doi.org/10.1002/qj.49712555502.
_ , and K. I. Hodges, 2001: African easterly wave variability and its relationship to Atlantic tropical cyclone activity. J. Climate, 14, 1166-1179, https://doi.org/10.1175/1520-0442(2001)014<1166: AEWVAI $>2.0 . \mathrm{CO} ; 2$.

Wheeler, M., and G. N. Kiladis, 1999: Convectively coupled equatorial waves: Analysis of clouds and temperature in the wavenumberfrequency domain. J. Atmos. Sci., 56, 374-399, https://doi.org/ 10.1175/1520-0469(1999)056<0374:CCEWAO>2.0.CO;2.

—,- , and P. Webster, 2000: Large-scale dynamical fields associated with convectively coupled equatorial waves. J. Atmos. Sci., 57, 613-640, https://doi.org/10.1175/1520-0469(2000)057<0613: LSDFAW $>2.0 . \mathrm{CO} ; 2$.

Yang, G.-Y., and B. J. Hoskins, 1996: Propagation of Rossby wave of nonzero frequency. J. Atmos. Sci., 53, 2365-2378, https://doi.org/ 10.1175/1520-0469(1996)053<2365:PORWON>2.0.CO;2.

— ated tropical convection. J. Atmos. Sci., 70, 3513-3532, https:// doi.org/10.1175/JAS-D-13-081.1.

— and - 2016: ENSO-related variation of equatorial MRG and Rossby waves and forcing from higher latitudes. Quart. J. Roy. Meteor. Soc., 142, 2488-2504, https://doi.org/10.1002/qj.2842.

,$- \ldots$, and J. M. Slingo, 2003: Convectively coupled equatorial waves: A new methodology for identifying wave structures in observational data. J. Atmos. Sci., 60, 1637-1654, https://doi.org/ 10.1175/1520-0469(2003)060<1637:CCEWAN >2.0.CO;2.

,$- \ldots$, and - 2007a: Convectively coupled equatorial waves. Part I: Horizontal structure. J. Atmos. Sci., 64, 34063423, https://doi.org/10.1175/JAS4017.1.

- - , and,$- 2007 \mathrm{~b}$ : Convectively coupled equatorial waves. Part II: Zonal propagation. J. Atmos. Sci., 64, 34243437, https://doi.org/10.1175/JAS4018.1.

,-- , and $-2007 \mathrm{c}$ : Convectively coupled equatorial waves. Part III: Synthesis structures and extratropical forcing. J. Atmos. Sci., 64, 3438-3451, https://doi.org/10.1175/JAS4019.1.

_ - J. Slingo, and B. J. Hoskins, 2009: Convectively coupled equatorial waves in high-resolution Hadley Centre climate models. J. Climate, 22, 1897-1919, https://doi.org/10.1175/2008JCLI2630.1.

_ B. B. Hoskins, and J. M. Slingo, 2011: Equatorial waves in opposite QBO phases. J. Atmos. Sci., 68, 839-862, https://doi.org/ 10.1175/2010JAS3514.1.

— - _ , and L. Gray, 2012: The influence of the QBO on the propagation of equatorial waves into the stratosphere. J. Atmos. Sci., 69, 2959-2982, https://doi.org/10.1175/JAS-D-11-0342.1.

Zhang, C., and P. J. Webster, 1989: Effects of zonal flows on equatorially trapped waves. J. Atmos. Sci., 46, 3632-3652, https://doi.org/ 10.1175/1520-0469(1989)046<3632:EOZFOE $>2.0 . C O ; 2$. 